\title{
Temperature Evolution of the Double Umbrella Magnetic Structure in Terbium Iron Garnet
}

\author{
Mahieddine Lahoubi \\ Badji Mokhtar-Annaba University, Faculty of Sciences, Department of Physics, Annaba \\ Algeria
}

\section{Introduction}

The rare earth iron garnets $\mathrm{RE}_{3} \mathrm{Fe}_{5} \mathrm{O}_{12}$ (REIG hereafter) have been discovered at Grenoble (France) (Bertaut \& Forrat, 1956; Bertaut et al., 1956) then independently at Murray Hill (USA) (Geller \& Gilleo, 1957a, 1957b). These most studied ferrimagnetic materials have a general formula $\left\{\mathrm{RE}^{3+}{ }_{3}\right\}\left[\mathrm{Fe}^{3+}{ }_{2}\right]\left(\mathrm{Fe}^{3+}{ }_{3}\right) \mathrm{O}_{12}$ where $\mathrm{RE}^{3+}$ can be any trivalent rare earth ion or the Yttrium $\mathrm{Y}^{3+}$. The crystal structure is described by the cubic space group Ia $\overline{3} \mathrm{~d}-\left(\mathrm{O}_{h}{ }^{10}\right)$ No. 230. Three type of brackets are used to indicate the different coordinations of the cations with respect to the oxygen $\mathrm{O}^{2-}$ ions situated in the general positions $\mathrm{x}, \mathrm{y}, \mathrm{z}$ of the sites $96 \mathrm{~h}(1)$ (Fig. 1). The $\mathrm{RE}^{3+}$ ions are located in the dodecahedral sites $\{24 \mathrm{c}\}(222)$ whereas the two $\mathrm{Fe}^{3+}$ ions are distributed in the octahedral $[16 \mathrm{a}](\overline{3})$ and tetrahedral $(24 \mathrm{~d})(\overline{4})$ sites.

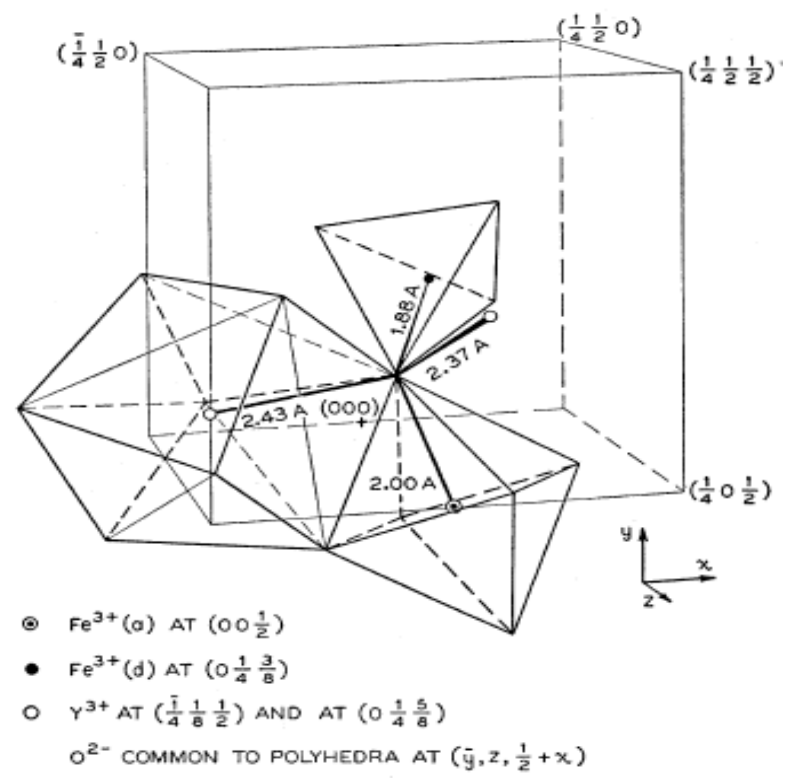

Fig. 1. Crystallographic sites of YIG in the space group Ia $\overline{3} \mathrm{~d}$ (Geller \& Gilleo, 1957b) 
It is a rather loose structure with a volume of $236.9 \AA^{3}$ per formula unit, which has the great technical advantage that it is possible to accommodate a very large variety of cations in the garnet structure. Thus, it is feasible to achieve an enormous range of control of the magnetic properties in the garnet structure system. The largest of REIG that can be formed is SmIG with a lattice parameter of $12.529 \AA$ and the smallest is LuIG with a lattice parameter of $12.283 \AA$. The REIG have became these famous magnetic compounds by illustrating the Néel theory of ferrimagnetism (Néel, 1948). The strongest superexchange interactions between the two iron sublattices $\mathrm{Fe}^{3+}[\mathrm{a}]-\mathrm{Fe}^{3+}(\mathrm{d})$ are antiferromagnetic and the magnetic moment vectors $m_{\mathrm{a}}$ and $m_{\mathrm{d}}$ are antiparallel. They make YIG, an ideal ferrimagnet with the Néel temperature $\left(T_{\mathrm{N}}\right)$ equal to $560 \mathrm{~K}$ (Pauthenet, 1958a, 1958b). However, substitution of a magnetic rare earth ion for the diamagnetic $\mathrm{Y}^{3+}$ in YIG introduces a third sublattice in the crystallographic site $\{c\}$ in which $m_{\mathrm{RE}}$ are the magnetic moment vectors. In this three sublattices model only weaker and negative antiferromagnetic interactions $\mathrm{RE}^{3+}\{\mathrm{c}\}-\mathrm{Fe}^{3+}(\mathrm{d})$ exist. If $M_{\mathrm{a}}, M_{\mathrm{d}}$ and $M_{\mathrm{RE}}$ are the magnetizations of each sublattice, the total bulk ferrite magnetization of REIG is given by the following equation

$$
M(\mathrm{REIG})=\left|M_{\mathrm{RE}}-\left(M_{\mathrm{d}}-M_{\mathrm{a}}\right)\right|
$$

For the heavier $\mathrm{RE}^{3+}$ ions $\left(\mathrm{Eu}^{3+}, \ldots, \mathrm{Yb}^{3+}\right), M_{\mathrm{RE}}$ is antiparallel to the net resultant of the iron magnetizations $M_{\mathrm{Fe}}=M_{\mathrm{d}}-M_{\mathrm{a}}$. We can consider that if we have $M_{\mathrm{Fe}} \approx M(\mathrm{YIG})$ then the interactions between the rare earth ions are negligible and the equation (1) becomes in a first approximation

$$
M(\mathrm{REIG})=\left|M_{\mathrm{RE}}-M_{\mathrm{Fe}}\right| \approx\left|M_{\mathrm{RE}}-M_{\mathrm{YIG}}\right|
$$

The magnetizations $M_{\mathrm{a}}$ and $M_{\mathrm{d}}$ are still given by the N.M.R values found in YIG (Gonano et al., 1967). Below $T_{N}$ which is nearly the same for all REIG compounds $(554 \pm 6) \mathrm{K}$ (Pauthenet, 1958a, 1958b) the magnetization of the rare earth ions $M_{\mathrm{RE}}$ can dominate the magnetization $M_{\mathrm{Fe}}$. If the temperature is decreasing, a rapid increasing of $M_{\mathrm{RE}}$ is observed because of the large magnetic moment $m_{\mathrm{RE}}$. In heavy rare earth iron garnets, there exists a compensation temperature $\left(T_{\text {comp }}\right)$ or inversion temperature $\left(T_{\mathrm{I}}\right)$ (Herpin, 1968) at which the bulk ferrite magnetization vanishes. For TbIG, $T_{\text {comp }}$ is equal to $(243.5 \pm 0.5 \mathrm{~K})$ and $(249.0 \pm$ $0.5 \mathrm{~K}$ ) for the single crystal and powder samples respectively (Lahoubi et al., 1985; Lahoubi, 1986). In the vicinity of $T_{\text {comp, }}$ the magnetic behavior is equivalent to that observed in the antiferromagnet compounds with the existence of the so-called field induced phase transitions which have been studied previously theoretically and experimentally (Zvezdin, 1995). In the Néel model, the $\mathrm{RE}^{3+}$ magnetic behavior is described by the pure free ion Brillouin function assuming that the superexchange interactions are represented by the isotropic Weiss molecular field coefficients.

The optical and magneto-optical (MO) properties of REIG and their substituted compounds have also received a substantial interest due to their strong Faraday and Kerr effects. The REIG had their first industrial use in bubble memories more than twenty years ago. Today, these MO materials are the key elements of several technical applications. There are used in Faraday rotators, optical isolators, holographic storage and magnetic field sensors. These applications can be enhanced by using photonic crystals with REIG and such research has yielded promising results. Recently, an additional interest to the REIG has been caused by the prospects for developing materials based on these ferrimagnets for hardware components in 
the next-generation spintronic devices. The fundamental properties of these REIG and their applications have been enormously reviewed previously and only a few authors are reported here (Dahlbäck, 2006; Geller, 1977; Guillot, 1995; Kazei et al., 1991). At low temperature when both crystal field acting on the $\mathrm{RE}^{3+}$ ions and the $\mathrm{RE}^{3+}\{\mathrm{c}\}-\mathrm{Fe}^{3+}(\mathrm{d})$ magnetic exchange anisotropies become important (Nekvasil \& Veltrusky, 1990), the Néel model must be replaced by a new spin configuration in which the $\mathrm{RE}^{3+}$ magnetic moments cease to be antiparallel to the $\mathrm{Fe}^{3+}$ magnetization $M_{\mathrm{Fe}}$. So, neutron diffraction experiments have been performed previously to study, the non collinear magnetic structures of the $\mathrm{RE}^{3+}$ moments $(\mathrm{RE}=\mathrm{Dy}, \mathrm{Er}$, $\mathrm{Ho}, \mathrm{Tb}, \mathrm{Tm}$ and $\mathrm{Yb}$ ) which appear at liquid-helium temperatures (Bertaut et al., 1970; Guillot et al., 1982; Herpin et al., 1960; Hock et al., 1990, 1991; Lahoubi et al., 1984; Lahoubi, 1986, 2012; Pickart et al., 1970; Tchéou et al., 1970a, 1970b). Neutron diffractions experiments have been also made to follow the temperature dependence of these "umbrella" magnetic structures in HoIG (Guillot et al., 1983, 1984), ErIG (Hock et al., 1991), DyIG (Lahoubi et al., 2009, 2010).

In the present chapter, we will present the temperature evolution of the $\mathrm{Tb}^{3+}$ magnetic ordering in TbIG using powder neutron diffraction experiments combined with magnetic field magnetization measurements on single crystal (Lahoubi et al., 1984, 1985; Lahoubi, 1986; Lahoubi et al., 1997; Lahoubi, 2012). The experimental techniques are described in the section 2. The principle of the non-polarized neutrons diffraction with the preliminarily experiment at $614 \mathrm{~K}$ are introduced in the main section 3. The neutron diffraction results obtained at high and low temperatures are discussed using the predictions of the symmetry analysis and compared with the data of magnetization measurements in the sections 4 and 5 respectively. The "Representation Analysis" of Bertaut (Bertaut, 1968, 1971, 1972) is applied to the paramagnetic space group Ia $\overline{3} \mathrm{~d}$ for determining all possible "umbrella" magnetic structures in this "cubic description". The method of the so-called "symmetry lowering device" (Bertaut, 1981) is required in the treatment for the determination of the best subgroups of Ia $\overline{3} \mathrm{~d}$ when the temperature is decreasing below $T_{\mathrm{N}}$ until liquid-helium temperatures. The "basis vectors of irreductible representations" of the distorted space group $\mathrm{R} \overline{3} \mathrm{c}$ are chosen in the "rhombohedral description". The thermal variations of the parameters of the "double umbrella" magnetic structure constitute the section 6 which will be followed by a conclusion in the section 7 .

\section{Experimental techniques}

The neutron diffraction experiments were measured on polycrystalline sample of TbIG owing to some severe extinctions which appear when a high quality single crystal is used (Bonnet et al., 1979). The first set of patterns have been recorded previously at the Centre d'Etudes Nucleaires de Grenoble (CENG) CEA Grenoble, France (Lahoubi et al., 1984; Lahoubi, 1986; Lahoubi et al., 1997) using the famous "Position Sensitive Detector" (PSD) detector (Convert et al., 1983; Roudaut et al., 1983). For the study, ten temperatures are chosen in the cryostat: 4.2, $20,54,68,80,109 \pm 2,127 \pm 5,160,208 \pm 2$ and around $T_{\text {comp }}$ at $244 \pm 10 \mathrm{~K}$. In the furnace, the temperatures are: above $T_{\mathrm{N}}(T=614 \mathrm{~K})$ and below $T_{\mathrm{N}}(T=283,400$ and $453 \mathrm{~K})$. The time of counting for some temperatures has been in the order of ten hours. The patterns were recorded with a wavelength $\lambda$ equal to $2.49 \AA$ and filters to avoid $\lambda / 2$ contaminations are used. The second set of patterns has been collected recently on the high flux diffractometer D1B at the Institut Laue-Langevin Grenoble, France. The value of the wavelength $\lambda$ is equal to $2.52 \AA$ and four temperatures 5, 13, 20 and $160 \mathrm{~K}$ have been chosen below room temperature. The resolution of the multidetector is $0.2^{\circ}$. For the magnetic study, the magnetization of a flux- 
grown single crystal of TbIG was measured in dc magnetic fields produced either by a superconducting coil up to $80 \mathrm{kOe}$ or a Bitter coil up to 150 and $200 \mathrm{kOe}$. The first series of experiments was performed at the Louis Néel Laboratory of Grenoble, France (currently Néel Institut) and the second series at the Service National des Champs Intenses (SNCI) of Grenoble (currently LNCMI). In the 4.2-300 K temperature range, the external magnetic field was applied parallel to the crystallographic directions $\langle 111\rangle,\langle 110\rangle$ and $<100\rangle$ successively. The spherical sample with $5.5 \mathrm{~mm}$ of diameter and $0.4313 \mathrm{~g}$ of weight is oriented along these three main crystallographic directions by the X-ray Laüe technique with an error less than $1^{\circ}$. The isothermal magnetizations $M_{\mathrm{T}}(H)$ as a function of internal magnetic field $H$ (the external magnetic field $H_{\mathrm{ex}}$ minus the demagnetizing magnetic field of the sphere $H_{\mathrm{d}}$ ) are analyzed by the least-squares refinement technique. The measured spontaneous magnetizations $M_{S}{ }^{\text {mes }}(T)$ are reported in $\left(\mu_{\mathrm{B}} / \mathrm{mol}\right)$ where one mole is equal to $2(\mathrm{TbIG})$ formula units.

\section{Principle of neutron diffraction}

We present here only the case of the diffraction of the non-polarized (or unpolarized) neutrons. This method was used firstly in the determination of the magnetic structure in MnO (Shull \& Smart, 1949). A multitude of others followed after: approximately thousands of magnetic structures have now been solved. The use of polarized neutrons ten years after has been the next progress in magnetic neutron scattering (Nathans et al., 1959). In this second method, the incident neutron beam is polarized either up or down, and the neutron intensities scattered by the sample are compared for the two possible states of the incident polarization. Compared to the non-polarized neutrons experiments, an interference term between the nuclear and the magnetic amplitudes adds or subtracts to the intensities depending on the direction of the polarization. For small magnetic amplitudes, the enhancement of sensitivity is remarkable and we know in the case of ferromagnetic and ferrimagnetics to determine the form factor of the magnetic atoms and to reconstruct the spin (or magnetization) density within the cell. Such investigations are now very common: several hundred spin density investigations have already been performed. In YIG (Bonnet et al., 1979), the polarized neutrons were used in addition to the study of the covalency effects. A book edited recently (Chatterji, 2006) is mostly devoted to the application of polarized neutron scattering from magnetic materials.

\subsection{Non-polarized neutrons diffraction: Determination of the diffracted intensities}

The scattering of neutron by a magnetic atom is composed essentially of two terms: a nuclear neutron scattering and a magnetic neutron scattering. The first term is due to a "neutron-nucleus" nuclear interaction giving the nuclear diffraction which yields information on the spatial arrangement of the nuclei of the atoms in crystal. In the second term, the neutron has a magnetic moment which can interact with the unpaired electrons of the magnetic atoms through the "dipole-dipole" interaction conducting to the magnetic diffraction (Bacon, 1975). The nuclear and the magnetic neutron scattering are incoherent in our non-polarized neutrons diffraction. For a magnetic material in the paramagnetic state obtained at $T>T_{\mathrm{N}}$, there is no magnetic contribution and only the nuclear diffraction exists with the diffracted nuclear intensity $\left(I_{\mathrm{N}}\right)$. The total diffracted intensity $I\left(T>T_{\mathrm{N}}\right)$ is equal to

$$
I\left(T>T_{\mathrm{N}}\right)=I_{\mathrm{N}}
$$


In the ordered magnetic state $\left(T<T_{\mathrm{N}}\right)$ a magnetic intensity $\left(I_{\mathrm{M}}\right)$ is added to the intensity $I_{\mathrm{N}}$.

We can measure finally the total diffracted intensity $I\left(T<T_{\mathrm{N}}\right)$ with the following equation

$$
I\left(T<T_{\mathrm{N}}\right)=I_{\mathrm{N}}+I_{\mathrm{M}}
$$

The diffracted magnetic intensity $I_{\mathrm{M}}$ is then obtained by the difference

$$
I_{\mathrm{M}}\left(T<T_{\mathrm{N}}\right)=I-I_{\mathrm{N}}
$$

This method is applied if we have a good counting statistics and also if $I_{\mathrm{M}}$ is not too lower then $I_{\mathrm{N}}$. We will recall briefly the following useful expressions of the nuclear and magnetic diffracted intensities for the case of a polycrystalline sample.

\subsubsection{Nuclear intensity $/ \mathbb{N}$}

In the paramagnetic state, the nuclear intensity $I_{\mathrm{N}}(\boldsymbol{H})$ can be calculated through the nuclear structure factor $F_{\mathrm{N}}(\boldsymbol{H})$ with the following expressions

$$
\begin{gathered}
I_{\mathrm{N}}(\boldsymbol{H})=P(\boldsymbol{H})\left|F_{\mathrm{N}}(\boldsymbol{H})\right|^{2} \\
F_{\mathrm{N}}(\boldsymbol{H})=\sum_{\mathrm{j}=1}^{\mathrm{N}} \mathrm{b}_{\mathrm{j}} \exp \left(2 \pi \mathrm{i} \boldsymbol{H} \cdot \boldsymbol{r}_{\mathrm{j}}\right) \exp \left(-\mathrm{B}_{\mathrm{j}}|\boldsymbol{H}|^{2} / 2\right)
\end{gathered}
$$

with $P(\boldsymbol{H})$, the multiplicity of the reflector plane, and $\boldsymbol{H}$, the corresponding scattering vector which is concentrated in the Bragg peaks (hkl) of the reciprocal lattice, $b_{j}$ and $B_{j}$ being respectively the neutron scattering length and the Debye-Waller factor of the $j^{\text {th }}$ atom in the $\mathrm{j}^{\text {th }}$ position vector $r_{\mathrm{j}}$ among $\mathrm{N}$, the total number of atoms in the crystallographic unit cell. The nuclear structure factor appears as a scalar factor.

\subsubsection{Magnetic intensity $I_{\mathrm{M}}$}

When the materials are magnetically ordered, the magnetic diffracted intensity $I_{M}(H)$ has the same form that found before for $I_{\mathrm{N}}(\boldsymbol{H})$ but we consider only the perpendicular component to $\boldsymbol{H}$ of the magnetic structure factor $\boldsymbol{F}_{\mathrm{M}}(\boldsymbol{H})$. We can write these equations

$$
\begin{gathered}
I_{\mathrm{M}}(\boldsymbol{H})=\left.|| \boldsymbol{F}_{\mathrm{M}}(\boldsymbol{H})\right|^{2}-\left|\boldsymbol{H} \cdot \boldsymbol{F}_{\mathrm{M}}(\boldsymbol{H})\right|^{2} /|\boldsymbol{H}|^{2} \mid \\
\boldsymbol{F}_{\mathrm{M}}(\boldsymbol{H})=\eta \sum_{\mathrm{j}=1}^{N} S_{\mathrm{j}_{\mathrm{j}}}(\boldsymbol{H}) \exp \left(2 \pi i \boldsymbol{H} \cdot \boldsymbol{r}_{\mathrm{j}}\right) \exp \left(-\mathrm{B}_{\mathrm{j}}|\boldsymbol{H}|^{2} / 2\right)
\end{gathered}
$$

with $\mathrm{f}_{\mathrm{j}}(\boldsymbol{H})$, the magnetic form factor of the jth spin $S_{j}$, and $\eta=|\gamma| \mathrm{e}^{2} / 2 \mathrm{~m}_{0} \mathrm{c}=+0.02696 \mathrm{~cm}$, the magnetic diffusion length $(\gamma=-1.91348)$. The magnetic structure factor has a vector form.

\subsubsection{Observed $I_{\text {obs }}$ and calculated $I_{\text {cal }}$ intensities}

The observed diffracted intensity $I_{\mathrm{obs}}$ is integrated on number of counts. The value (in barns) is corrected by the Lorentz factor $L(\boldsymbol{H})$ and normalized by the scale factor $K$ where the definitions are expressed respectively by the following equations 


$$
L(H)=1 / \sin \theta \sin (2 \theta) ; K=I_{\text {cal }} / I_{\text {obs }}
$$

The value of $K$ is obtained by the refinement of the nuclear structure. For each $I_{\mathrm{obs}}$, an absolute error $\Delta I_{\text {obs }}$ is found. She is associated to the sum of a statistical error with the appreciated one on the continu fund noise. The corresponding observed relative error is noted $\Delta I_{\text {obs }} / I_{\text {obs. }}$ Using the least square method, we can define the reliability factor $R$

$$
R=\sum\left|I_{\mathrm{obs}}-I_{\text {cal }}\right| / \sum\left|I_{\mathrm{obs}}\right|
$$

For each calculated diffracted intensity $I_{\text {cal, }}$ a calculated relative error $\Delta I_{\text {cal }} / I_{\text {cal }}$ is attributed. The non-polarized neutron diffraction is then based in the comparison between $I_{\mathrm{cal}}$ and $I_{\mathrm{obs}}$.

\subsection{Preliminarily neutron diffraction at $614 \mathrm{~K}$}

In the pattern (not show) recorded at $T=614 \mathrm{~K}$ higher than $T_{\mathrm{N}}(568 \pm 2 \mathrm{~K}$ ) (Pauthenet, 1958a, $1958 \mathrm{~b}$ ), only the nuclear contribution exists and the reflections (hkl) are indexed with the general extinction rule of the cubic space group Ia $\overline{3} \mathrm{~d}, \mathrm{~h}+\mathrm{k}+\mathrm{l}=2 \mathrm{n}$. Attention was paid to the thermal agitation of the $\mathrm{j}^{\text {th }}$ atom in the different sites by introducing the corresponding isotropic Debye-Waller factors $B_{j}$. For the determination of the calculated nuclear intensities $\left(I_{\mathrm{N}}\right)_{\mathrm{cal}}$, the previous scattering lengths (Bacon, 1972) are used: $\mathrm{b}(\mathrm{O})=0.580 ; \mathrm{b}(\mathrm{Fe})=0.95 ; \mathrm{b}(\mathrm{Tb})$ $=0.76$ (in units of 10-12 cm/atom). We can determine the number of refinement cycles and to choose the parameters with a sufficient number of iterations. The previous best values of the parameters $\mathrm{x}=-0.0279, \mathrm{y}=0.0555, \mathrm{z}=0.1505$ found previously at $T=693 \mathrm{~K}$ (Tchéou et al., 1970c) for the general positions (96h) of the oxygen atoms are used as constant parameters and the refinement is made only on the scale factor $K$ and after the corresponding isotropic Debye-Waller factors $B_{j}$. A good agreement with a reliability factor of order $10 \%$ is found for the lattice parameter $a=12.470 \pm 0.004 \AA$ and $K=0.42 \pm 0.02$ with $\mathrm{B}_{\mathrm{h}}(\mathrm{O})=0.88 ; \mathrm{B}_{\mathrm{d}}(\mathrm{Fe})=$ $\mathrm{B}_{\mathrm{a}}(\mathrm{Fe})=0.82$ and $\mathrm{B}_{\mathrm{c}}(\mathrm{Tb})=0.81$. We observe that the observed intensities of the reflections (400) and (420) are lower than the corresponding calculated intensities and the refinement of the temperature parameters $B_{j}$ has a little influence on the values of the observed intensities (for example when $\mathrm{B}_{\mathrm{c}}(\mathrm{Tb})$ change from 0.80 to 0.30 ).

\section{Neutron diffraction study at high temperature}

The neutron diffraction patterns below $T_{\mathrm{N}}$ are reported in Fig. 2 for 453 and $400 \mathrm{~K}$. Both patterns at $(283 \mathrm{~K})$ and at $5 \mathrm{~K}(\mathrm{D} 1 \mathrm{~B})$ are presented for a useful comparison in Fig. 3. A magnetic intensity $I_{\mathrm{M}}(\mathrm{hkl})$ is superimposed to the nuclear intensity $I_{\mathrm{N}}(\mathrm{hkl})$ : we have then, $I(\mathrm{hkl})=I_{\mathrm{N}}(\mathrm{hkl})+I_{\mathrm{M}}(\mathrm{hkl})$. In these patterns, we have indexed all the reflections (hkl) in the chemical cell with the same extinction rule characterized by a wave vector $k=0$. In these temperatures, the magnetic structure factors $\boldsymbol{F}_{\mathrm{M}}(\mathrm{a})(\mathrm{hkl}), \boldsymbol{F}_{\mathrm{M}}{ }^{(\mathrm{d})}(\mathrm{hkl})$ and $\boldsymbol{F}_{\mathrm{M}}(\mathrm{c})(\mathrm{hkl})$ associated to each magnetic sublattice of TbIG are used to describe the collinear ferrimagnetic state of the Néel model along the easy axis [111] found by magnetization measurements (Lahoubi et al., 1985 and refs. herein). Two types of reflections (hkl) appear in the patterns: ( $h=$ odd, $\mathrm{k}=$ odd, $1=$ even) and $\mathrm{h}=$ even, $\mathrm{k}=$ even, $\mathrm{l}=$ even). For the related reflections (hkl) with $(\mathrm{h}=$ even, $\mathrm{k}=$ odd, $\mathrm{l}=\mathrm{odd})$ and $(\mathrm{h}=\mathrm{odd}, \mathrm{k}=$ even, $\mathrm{l}=\mathrm{odd})$ and cyclic permutations (c.p.) of $\mathrm{h}, \mathrm{k}$, 1 must be done in the expressions of the magnetic structure factors. A complete description can be found in the previous paper on the neutron diffraction of HoIG (Guillot et al., 1984). 


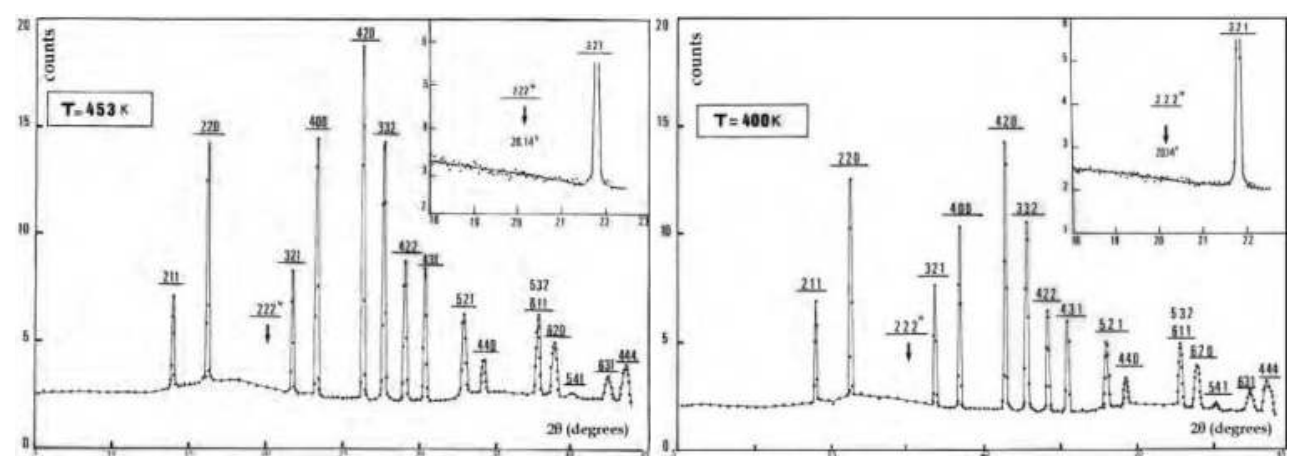

Fig. 2. Neutron diffraction patterns at 453 and $400 \mathrm{~K}$
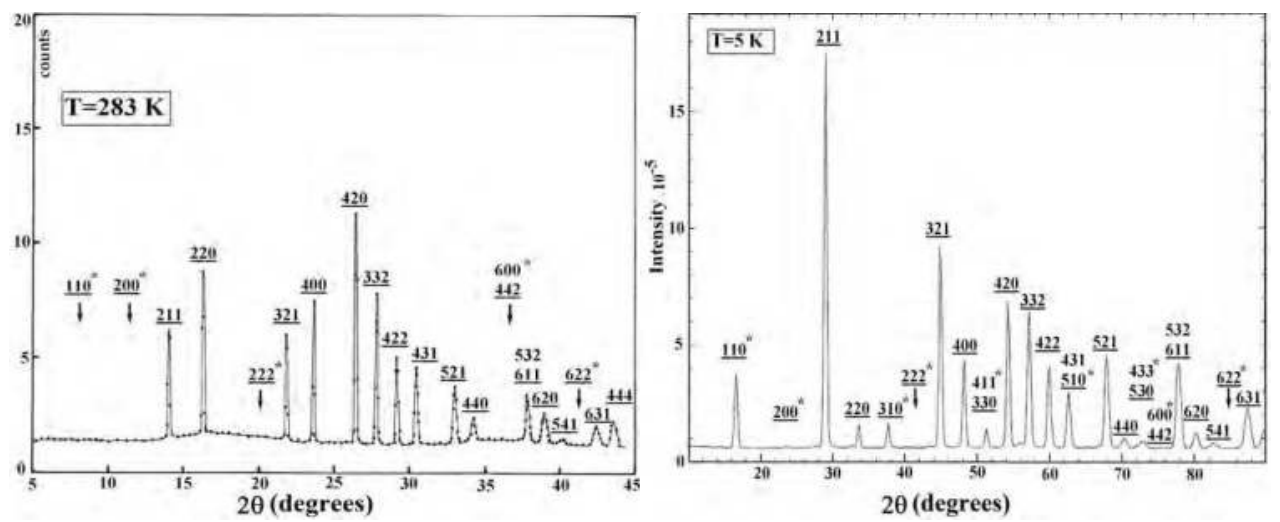

Fig. 3. Neutron diffraction patterns at 283 and $5 \mathrm{~K}$ (D1B)

\subsection{Results and discussion}

We have observed during the refinement that the calculated parameters $m_{\mathrm{Tb}}, m_{\mathrm{a}}$ and $m_{\mathrm{d}}$ of the three magnetic sublattices are depending highly of the choice of the magnetic form factors, $\mathrm{f}_{\mathrm{Tb}}(\mathrm{hkl})$ and particularly those related to the two iron sublattices $\mathrm{f}_{\mathrm{a}}(\mathrm{hkl})$ and $\mathrm{f}_{\mathrm{d}}(\mathrm{hkl})$. We choose at first, the theoretical magnetic form factors determined in the Hartree-Fock description based on the free ion model for the $\mathrm{Tb}^{3+}$ ion, $\mathrm{f}_{\mathrm{Tb}}(\mathrm{hkl})$ (Blume, et al., 1962) and those calculated (Watson \& Fremann, 1961) $f_{a}(h k l)$ and $f_{d}(h k l)$ with the equality $f_{a}(h k l)=f_{d}(h k l)$ for the iron sublattices. Secondly, two previous experimental magnetic form factors $f_{a}(h k l)$ and $f_{d}(h k l)$ are also tentatively used. The first values (Bonnet, 1976; Bonnet et al., 1979) obtained by polarized neutrons experiments on YIG single crystal indicate that $f_{a}(h k l)$ and $f_{d}(h k l)$ are different that the free ion value and $f_{a}(h k l)>f_{d}(h k l)$. The second values of $f_{a}(h k l)$ and $f_{d}(h k l)$ with the relation $\mathrm{f}_{\mathrm{a}}(\mathrm{hkl})<\mathrm{f}_{\mathrm{d}}(\mathrm{hkl})$ have been found previously by powder neutron diffraction experiments (Guillot et al., 1983). In the study of the "umbrella structure" at low temperature on HoIG sample prepared by grinding of single crystals (Guillot et al., 1984), an evaluation of $m_{\mathrm{a}}$ and $m_{\mathrm{d}}$ using the Bonnet' $\mathrm{f}_{\mathrm{a}}(\mathrm{hkl}), \mathrm{f}_{\mathrm{d}}(\mathrm{hkl})$ determinations was made. At $4.2 \mathrm{~K}$, these moments were found equal respectively to 4,01 and $4,26 \mu_{\mathrm{B}}$. These values are smaller than the theoretical ground state ${ }^{6} S_{5 / 2}$ saturated magnetic moment $\left(5 \mu_{\mathrm{B}}\right)$. The observed reduction of the moments 
is explained by covalent bonding for YIG (Bonnet, 1976; Fuess et al., 1976) or topological frustration for $\mathrm{FeF}_{3}$ (Ferey et al., 1986). When the proposed values (Guillot., et al 1983) are chosen in the refinement of the neutron diagrams at 453, 400 and $283 \mathrm{~K}$, we observe that the calculated intensities of the reflections (211) and (220) which have a high magnetic contribution are lower than the observed intensities. Consequently, we shall consider in this work for the $\mathrm{Fe}^{3+}$ ions only the theoretical values of $\mathrm{f}_{\mathrm{a}}(\mathrm{hkl})$ and $\mathrm{f}_{\mathrm{d}}(\mathrm{hkl})$ (Watson \& Fremann, 1961). In this condition, $m_{\mathrm{a}}$ and $m_{\mathrm{d}}$ are not considered as fitting parameters in the first cycle of the refinement and the N.M.R values are used (Gonano et al., 1967). Working in this hypothesis leads to the best values of $m_{\mathrm{Tb}}$ at each temperature. Finally, in the second cycle of the refinement based on twenty reflections, the parameters $m_{\mathrm{a}}$ and $m_{\mathrm{d}}$ are fitted by the selfconsistent calculation of $m_{\mathrm{Tb}}$. At 453 and $400 \mathrm{~K}$, we obtain respectively for $m_{\mathrm{Tb}}$ the refined values $0.50 \pm 0.10 \mu_{\mathrm{B}}$ and $0.60 \pm 0.10 \mu_{\mathrm{B}}$ with a reliability factor $R$ varying in the range of $11.8-$ 9.3 and $11.6-8.6 \%$ if the refinement is makes only on the twelve first reflections (Lahoubi, 1986). The results lead to a good agreement between the bulk calculated magnetizations $M_{S}$ cal (TbIG) and the observed spontaneous magnetization $M_{S}{ }^{o b s}(\mathrm{TbIG})$ (Pauthenet, 1958a, 1958b). The result at $283 \mathrm{~K}\left(1.15 \mu_{\mathrm{B}}\right.$ with $\left.R=8.5 \%\right)$ (Lahoubi, 1986) is similar to that found previously (Bonnet, 1976; Fuess et al., 1976) but with a poor agreement for $m_{\mathrm{a}}$ and $m_{\mathrm{d}}$ which have been found lower by comparison with those determined by N.M.R (Gonano et al., 1967).

\section{Neutron diffraction study at low temperature and symmetry analysis}

The neutron patterns recorded at 5 (D1B), 13 (D1B), 20, 54, 68, 80, 109, 127, 160, 208 and 244 K are presented from Fig. 3 up to Fig. 9.

\subsection{Results and discussion}

At $T=5 \mathrm{~K}$ (Fig. 3), two types of reflection appear. In addition to the earlier reflections (hkl) observed previously, pure superstructure lines $(\mathrm{hkl})^{*}$ forbidden by the nuclear space group Ia $\overline{3} \mathrm{~d}$ are present and we have $I=I_{\mathrm{M}}(\mathrm{hkl})^{*}:(110)^{*},(310)^{*},(411,330)^{*},(433,530)^{*}$ and $(510)^{*}$.

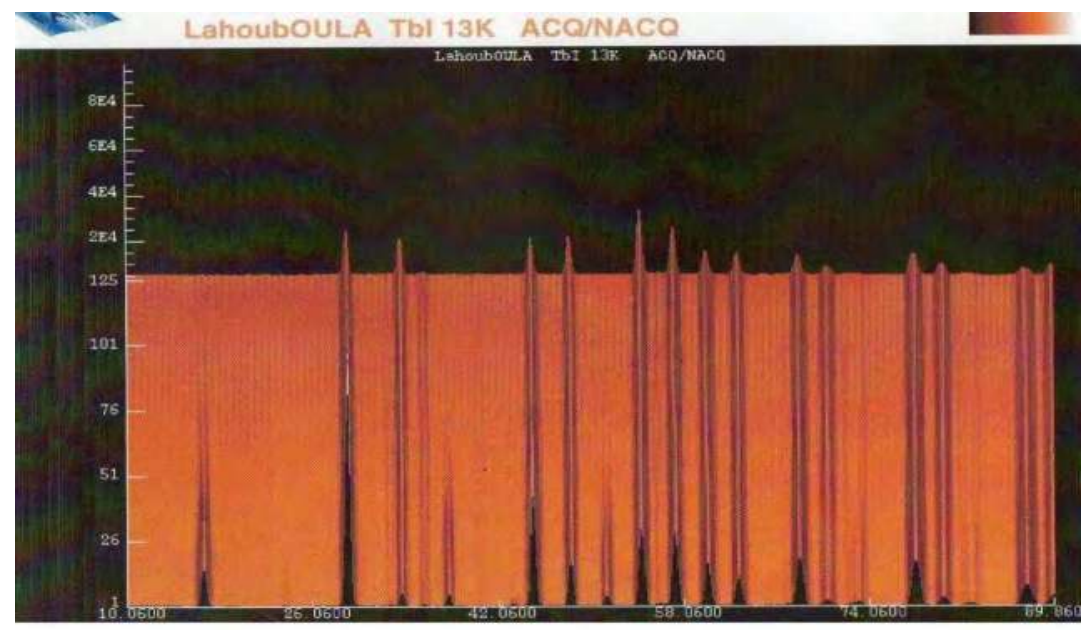

Fig. 4. Neutron diffraction pattern at $13 \mathrm{~K}$ (D1B) 
In contrast to previous findings at $1.5 \mathrm{~K}$ (Bertaut et al., 1970; Tchéou al., 1970a) and $4.2 \mathrm{~K}$ (Lahoubi et al., 1984), the small superstructure lines $(200)^{*}$ and $(600,442)^{*}$ have been observed recently and confirmed only at $5 \mathrm{~K}$ (D1B) (Lahoubi, 2012) with a sensibility equal to 0.5 and $1 \%$ respectively, the line $(110)^{*}$ being chosen as a reference. The same order of magnitude $(1 / 276)$ by comparison with the previous result (Hock et al., 1990) was found for the line (200)*. Above $5 \mathrm{~K}$, they are not observed in the neutron diffraction pattern at $13 \mathrm{~K}$ (Fig. 4).
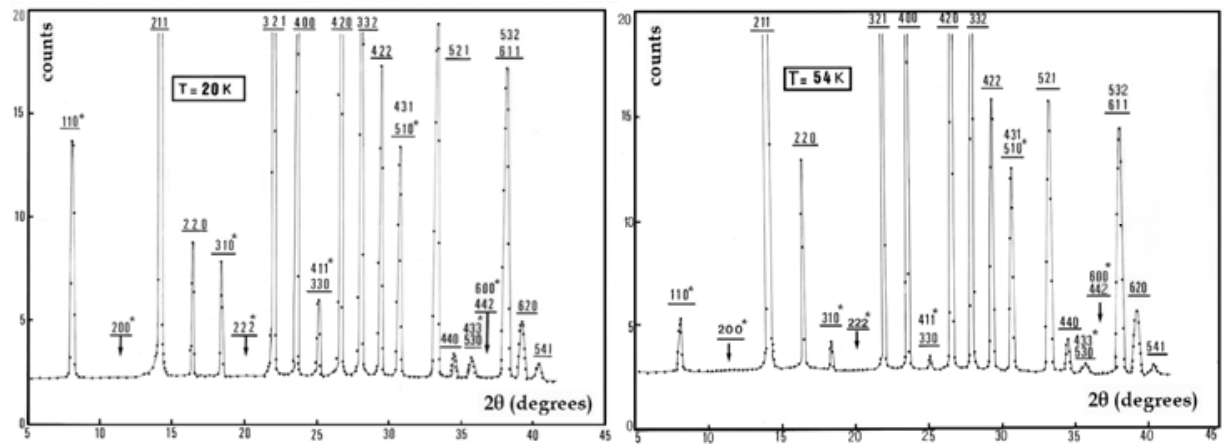

Fig. 5. Neutron diffraction patterns at 20 and $54 \mathrm{~K}$
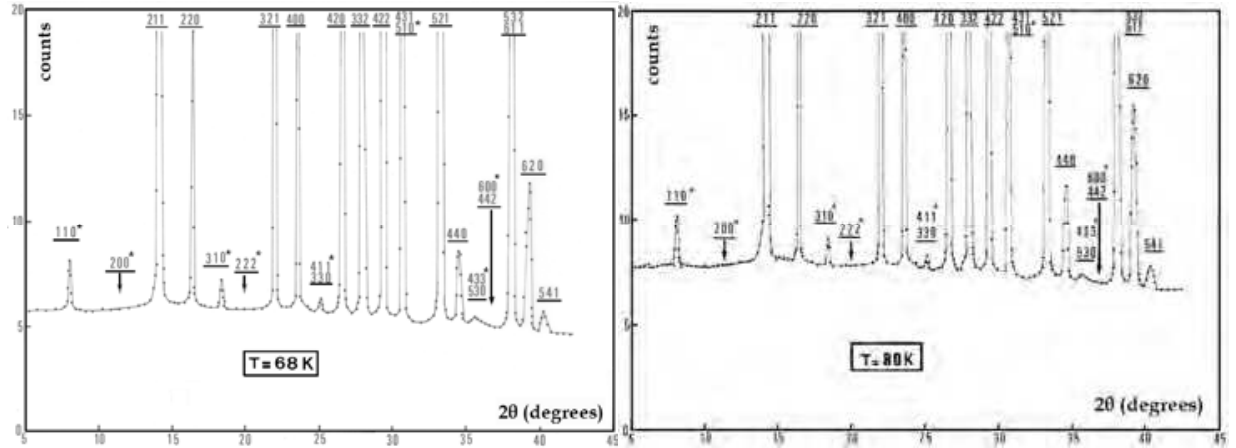

Fig. 6. Neutron diffraction patterns at 68 and $80 \mathrm{~K}$
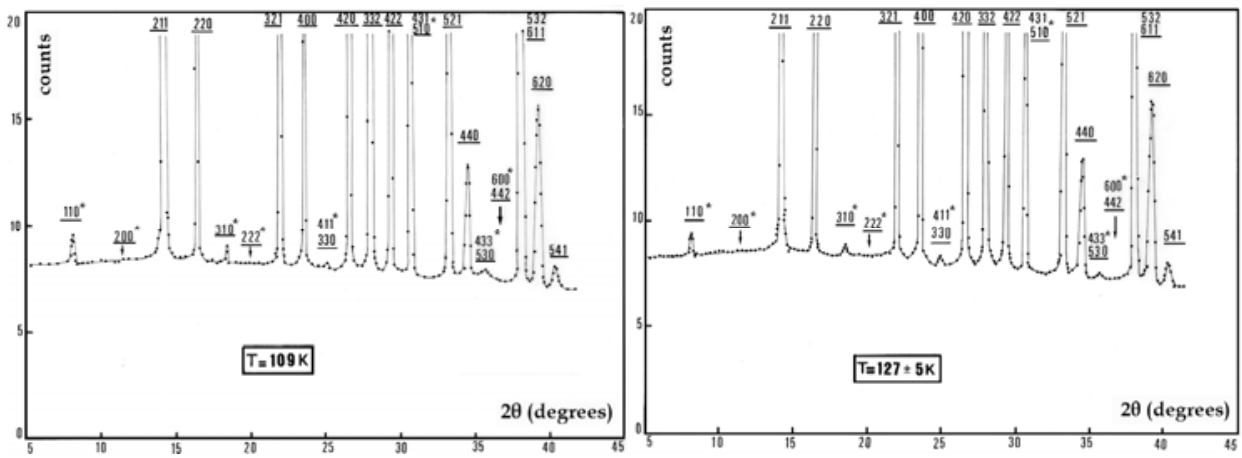

Fig. 7. Neutron diffraction patterns at 109 and $127 \pm 5 \mathrm{~K}$ 

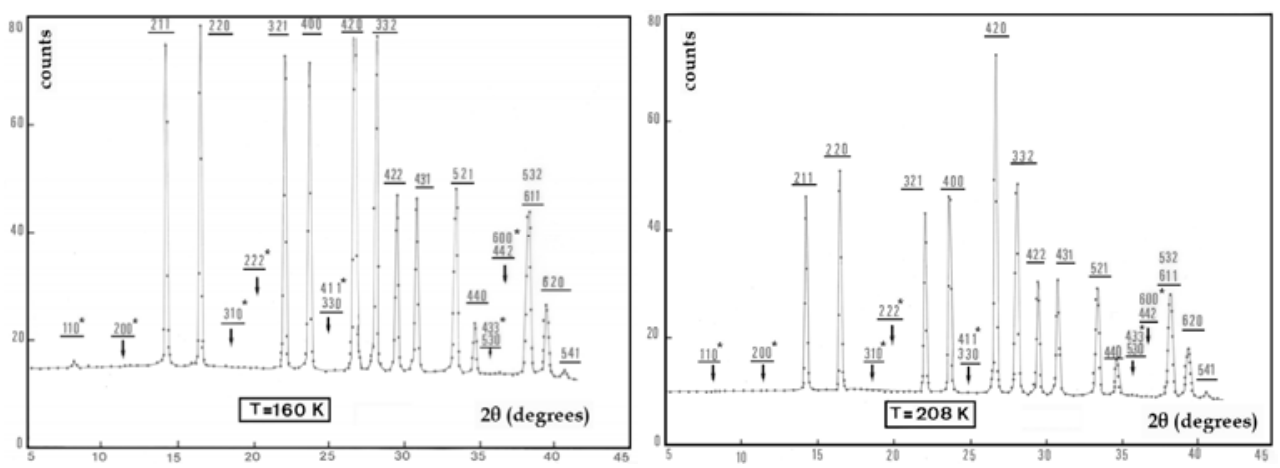

Fig. 8. Neutron diffraction patterns at 160 and $208 \mathrm{~K}$

All the superstructure lines appear without any ambiguity from $5 \mathrm{~K}$ up to $127 \pm 5 \mathrm{~K}$. They are indexed with the same extinction rule $\left(h^{*}+k^{*}+l^{*}=2 n\right)$ and imply the signature of a change of the collinear magnetic structure of the $\mathrm{RE}^{3+}\{24 \mathrm{c}\}$ ions of the Néel model to a non collinear magnetic structure with the wave vector $\boldsymbol{k}=0$. At 160 and $208 \mathrm{~K}$, the superstructure line $(110)^{*}$ is resolved with the best sensibility ( 0.3 and $1 \%$ respectively) which is equal to the ratio of the peak to background normalized to the intensity of the line (211) (see the details for $2 \theta$ up to $15^{\circ}$ in the left of Fig. 9).

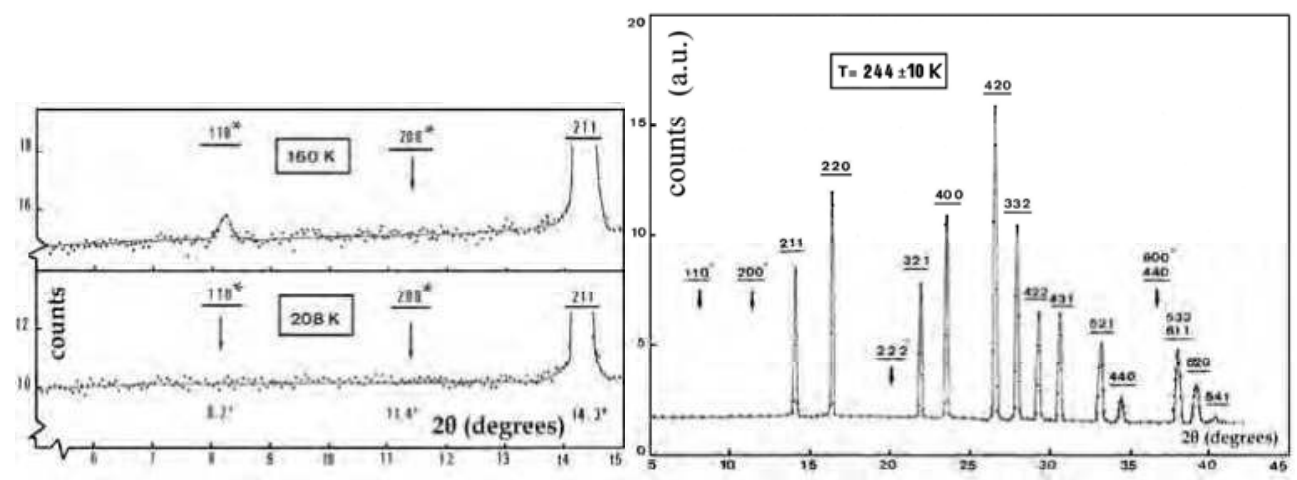

Fig. 9. Details at 160 and $208 \mathrm{~K}$ (left) and neutron diffraction pattern at $244 \pm 10 \mathrm{~K}$ (right)

The chemical cell is equal to the magnetic cell, thus the primitive translation noted $(1 \mid 1 / 2,1 / 2,1 / 2)$ of the crystallographic lattice (I) (Hahn, 1983) is a primitive translation of the magnetic lattice (I). Based on the numbered positions gathered on Table 1 we can write for the $\mathrm{RE}^{3+}\{24 \mathrm{c}\}$ and $\mathrm{Fe}^{3+}(24 \mathrm{~d})$ sublattices that $S_{\mathrm{j}}=S_{\mathrm{j}}+S_{\mathrm{j}+12}(\mathrm{j}=1-3)$; for $\mathrm{Fe}^{3+}[16 \mathrm{a}]$ sublattice, we have $S_{\mathrm{p}}=S_{\mathrm{p}}+S_{\mathrm{p}+8}(\mathrm{p}=1-4)$ and $S_{\mathrm{p}^{\prime}}=S_{\mathrm{p}^{\prime}}+S_{\mathrm{p}^{\prime}+8}\left(\mathrm{p}^{\prime}=5-8\right)$. It means that two spin vectors $S_{\mathrm{j}}, S_{\mathrm{j}+12}, S_{\mathrm{p}}, S_{\mathrm{p}+8}$ and $S_{\mathrm{p}^{\prime}}, S_{\mathrm{p}^{\prime}+8}$ are coupled ferromagnetically. To discuss the corresponding

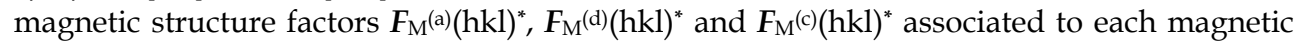
sublattice in TbIG, the four earlier linear combinations of four spin vectors introduced by Bertaut (Bertaut, 1963) labeled $F, G, C$ and $A$ are used. These four magnetic modes (one ferromagnetic and three antiferromagnetics) form the "basis of irreductible representations". 


\begin{tabular}{|c|c|c|c|c|c|c|}
\hline \multicolumn{3}{|c|}{$\begin{array}{l}\text { Notations } C_{j}, C^{\prime}(j=1-3) \text { and } \\
\{\mathrm{i}=1-6\} \text { (Wolf et al., 1962; Wolf, } \\
1964 \text { and Pearson et al., 1965) } \\
\text { Local axes in } \mathrm{D}_{2}(222) \text { symmetry } \\
U \quad g_{\mathrm{z}} \\
V \quad g_{\mathrm{x}}\left(g_{\mathrm{y}}\right) \\
W \quad g_{\mathrm{y}}\left(g_{\mathrm{x}}\right) \\
\text { Numbered positions of } \mathrm{RE}^{3+} \\
\text { ions in site }\{24 \mathrm{c}\}(222)\end{array}$} & \multicolumn{2}{|c|}{$\begin{array}{l}\text { Notations } D_{j}, D_{j}^{\prime}(j=1-3) \\
\text { Numbered positions of } \\
\mathrm{Fe}^{3+} \text { ions in site }(24 \mathrm{~d})(\overline{4})\end{array}$} & \multicolumn{2}{|c|}{$\begin{array}{l}\text { Unprimed and primed (') } \\
\text { notations respectively for } \mathrm{p} \\
=1-4 \text { and } \mathrm{p}^{\prime}=5-8 \text { with c.p. } \\
\text { Numbered positions of } \mathrm{Fe}^{3+} \\
\text { ions in site }[16 \mathrm{a}](\overline{3})\end{array}$} \\
\hline & $\begin{array}{l}100 \\
01 \overline{1} \\
011\end{array}$ & $\begin{array}{lr}\text { (1) } & 1 / 8,0,1 / 4 \\
\text { (7) } & 7 / 8,0,3 / 4 \\
\text { (13) } & 5 / 8,1 / 2,3 / 4 \\
\text { (19) } & 3 / 8,1 / 2,1 / 4 \\
\end{array}$ & $\mathrm{D}_{1}$ & \begin{tabular}{|lr} 
(1) & $3 / 8,0,1 / 4$ \\
(7) & $5 / 8,0,3 / 4$ \\
(13) & $7 / 8,1 / 2,3 / 4$ \\
(19) & $1 / 8,1 / 2,1 / 4$ \\
\end{tabular} & & $\begin{array}{lr}\text { (1) } & 0,0,0 \\
\text { (9) } & 1 / 2,1 / 2,1 / 2\end{array}$ \\
\hline \begin{tabular}{l|}
$C_{1}^{\prime}$ \\
2 \\
4
\end{tabular} & $\begin{array}{l}100 \\
011 \\
0 \overline{1} 1\end{array}$ & $\begin{array}{lr}\text { (4) } & 3 / 8,0,3 / 4 \\
\text { (10) } & 5 / 8,0,1 / 4 \\
\text { (16) } & 7 / 8,1 / 2,1 / 4 \\
\text { (22) } & 1 / 8,1 / 2,3 / 4 \\
\end{array}$ & $\mathrm{D}_{1}^{\prime}$ & \begin{tabular}{|lr}
$\mathbf{( 4 )}$ & $1 / 8,0,3 / 4$ \\
$\mathbf{( 1 0 )}$ & $7 / 8,0,1 / 4$ \\
$\mathbf{( 1 6 )}$ & $5 / 8,1 / 2,1 / 4$ \\
(22) & $3 / 8,1 / 2,3 / 4$ \\
\end{tabular} & & $\begin{array}{lr}\mathbf{( 2 )} & 0,1 / 2,1 / 2 \\
\mathbf{( 1 0 )} & 1 / 2,0,0\end{array}$ \\
\hline $\begin{array}{l}\mathrm{C}_{2} \\
3 \\
5\end{array}$ & $\begin{array}{l}010 \\
\overline{1} 01 \\
101\end{array}$ & $\begin{array}{lr}\text { (2) } & 1 / 4,1 / 8,0 \\
\text { (8) } & 3 / 4,7 / 8,0 \\
\text { (14) } 3 / 4,5 / 8,1 / 2 \\
\text { (20) } 1 / 4,3 / 8,1 / 2 \\
\end{array}$ & $\mathrm{D}_{2}$ & \begin{tabular}{|lr} 
(2) & $1 / 4,3 / 8,0$ \\
$\mathbf{( 8 )}$ & $3 / 4,5 / 8,0$ \\
$\mathbf{( 1 4 )}$ & $3 / 4,7 / 8,1 / 2$ \\
(20) & $1 / 4,1 / 8,1 / 2$ \\
\end{tabular} & & \begin{tabular}{|lr}
$\mathbf{( 3 )}$ & $1 / 2,0,1 / 2$ \\
$\mathbf{( 1 1 )}$ & $0,1 / 2,0$
\end{tabular} \\
\hline \begin{tabular}{l|}
$\mathrm{C}_{2}^{\prime}$ \\
4 \\
6
\end{tabular} & $\begin{array}{l}010 \\
101 \\
10 \overline{1}\end{array}$ & $\begin{array}{lr}\text { (5) } & 3 / 4,3 / 8,0 \\
\mathbf{( 1 1 )} & 1 / 4,5 / 8,0 \\
\mathbf{( 1 7 )} & 1 / 4,7 / 8,1 / 2 \\
\text { (23) } 3 / 4,1 / 8,1 / 2\end{array}$ & $\mathrm{D}_{2}^{\prime}$ & \begin{tabular}{|lr} 
(5) & $3 / 4,1 / 8,0$ \\
$\mathbf{( 1 1 )}$ & $1 / 4,7 / 8,0$ \\
$\mathbf{( 1 7 )}$ & $1 / 4,5 / 8,1 / 2$ \\
(23) $3 / 4,3 / 8,1 / 2$ \\
\end{tabular} & & \begin{tabular}{|lr}
$\mathbf{( 4 )}$ & $1 / 2,1 / 2,0$ \\
$\mathbf{( 1 2 )}$ & $0,0,1 / 2$
\end{tabular} \\
\hline $\begin{array}{l}\mathrm{C}_{3} \\
5 \\
1\end{array}$ & $\begin{array}{l}001 \\
1 \overline{1} 0 \\
110\end{array}$ & $\begin{array}{lr}\text { (3) } & 0,1 / 4,1 / 8 \\
\text { (9) } & 0,3 / 4,7 / 8 \\
\text { (15) } & 1 / 2,3 / 4,5 / 8 \\
\text { (21) } & 1 / 2,1 / 4,3 / 8 \\
\end{array}$ & $\mathrm{D}_{3}$ & $\begin{array}{|lr|}\text { (3) } & 0,3 / 4,3 / 8 \\
\text { (9) } & 0,3 / 4,5 / 8 \\
(15) & 1 / 2,3 / 4,7 / 8 \\
\text { (21) } & 1 / 2,3 / 4,3 / 8 \\
\end{array}$ & (') & $\begin{array}{ll}\text { (5) } & 1 / 4,1 / 4,1 / 4 \\
\text { (13) } & 3 / 4,3 / 4,3 / 4\end{array}$ \\
\hline \begin{tabular}{l|}
$\mathrm{C}_{3}^{\prime}$ \\
6 \\
2
\end{tabular} & $\begin{array}{l}001 \\
110 \\
110\end{array}$ & $\begin{array}{lr}\mathbf{( 6 )} & 0,3 / 4,3 / 8 \\
\mathbf{( 1 2 )} & 0,1 / 4,5 / 8 \\
\mathbf{( 1 8 )} & 1 / 2,1 / 4,7 / 8 \\
\mathbf{( 2 4 )} & 1 / 2,3 / 4,1 / 8 \\
\end{array}$ & $\mathrm{D}_{3}^{\prime}$ & \begin{tabular}{|lr}
$\mathbf{( 6 )}$ & $0,3 / 4,1 / 8$ \\
$\mathbf{( 1 2 )}$ & $0,1 / 4,7 / 8$ \\
$\mathbf{( 1 8 )}$ & $1 / 2,1 / 4,5 / 8$ \\
$\mathbf{( 2 4 )}$ & $1 / 2,3 / 4,3 / 8$ \\
\end{tabular} & (') & $\begin{array}{ll}\text { (6) } & 1 / 4,3 / 4,3 / 4 \\
\text { (14) } & 3 / 4,1 / 4,1 / 4\end{array}$ \\
\hline & & & & & (') & $\begin{array}{ll}\text { (7) } & 3 / 4,1 / 4,3 / 4 \\
(\mathbf{1 5}) & 1 / 4,3 / 4,1 / 4\end{array}$ \\
\hline & & & & & (') & $\begin{array}{ll}\text { (8) } & 3 / 4,3 / 4,1 / 4 \\
\text { (16) } & 1 / 4,1 / 4,3 / 4\end{array}$ \\
\hline
\end{tabular}

Table 1. Notations, numbers and positions in the unit cell of the three magnetic sublattices. $U, V$ and $W$ are the local axes of the $\mathrm{RE}^{3+}$ in D2(222) symmetry 
The adapted magnetic modes for the $\mathrm{RE}^{3+}\{24 \mathrm{c}\}$ and $\mathrm{Fe}^{3+}(24 \mathrm{~d})$ sublattices with $\mathrm{j}=1-3$ are

$$
\begin{aligned}
& F_{j}=S_{j}+S_{j+3}+S_{j+6}+S_{j+9} ; G_{j}=S_{j}-S_{j+3}+S_{j+6}-S_{j+9} ; \\
& C_{j}=S_{j}+S_{j+3}-S_{j+6}-S_{j+9} ; A_{j}=S_{j}-S_{j+3}-S_{j+6}+S_{j+9}
\end{aligned}
$$

For the $\mathrm{Fe}^{3+}[16 \mathrm{a}]$ sublattice, it is necessary to consider two distinct magnetic modes. The first chosen notation is the unprimed magnetic modes for the numbered spins $S_{\mathrm{p}}=S_{\mathrm{p}}+S_{\mathrm{p}+8}(\mathrm{p}=1-4)$

$$
\boldsymbol{F}=S_{1}+S_{2}+S_{3}+S_{4} ; G=S_{1}-S_{2}+S_{3}-S_{4} ; C=S_{1}+S_{2}-S_{3}-S_{4} ; A=S_{1}-S_{2}-S_{3}+S_{4}
$$

The second chosen notation of the magnetic modes is the primed notation (') for the numbered spins $S_{\mathrm{p}^{\prime}}=S_{\mathrm{p}^{\prime}}+S_{\mathrm{p}^{\prime}+8} \quad\left(\mathrm{p}^{\prime}=5-8\right)$

$$
F^{\prime}=S_{5}+S_{6}+S_{7}+S_{8} ; G^{\prime}=S_{5}-S_{6}+S_{7}-S_{8} ; C^{\prime}=S_{5}+S_{6}-S_{7}-S_{8} ; A^{\prime}=S_{5}-S_{6}-S_{7}+S_{8}
$$

For the $\mathrm{RE}^{3+}$ ions in the Wyckoff site $\{24 \mathrm{c}\}$, the local axes $(\boldsymbol{U}, \boldsymbol{V}, \boldsymbol{W})$ in the $\mathrm{D}_{2}(222)$ symmetry are identified to the parameters $g_{\alpha}(\alpha=x, y, z)$ of the magnetic tensor $\tilde{g}$ in the hypothesis of the effective spin Hamiltonian model (Wolf et al., 1962, Wolf, 1964). The particular superstructure lines $(222)^{*}$ and $(622)^{*}$ are not observed in the whole temperature range below $T_{\mathrm{N}}$. For example, the associated magnetic structure factors are all equal to zero

$$
\begin{gathered}
\boldsymbol{F}_{\mathrm{M}}{ }^{(\mathrm{a})}(222)^{*}=\boldsymbol{F}-\boldsymbol{F}^{\prime}=0 ; \boldsymbol{F}_{\mathrm{M}}{ }^{(\mathrm{d})}(222)^{*}=+\mathrm{i}\left(A_{1}+A_{2}+A_{3}\right)=0 \\
\boldsymbol{F}_{\mathrm{M}}{ }^{(\mathrm{c})}(222)^{*}=-\mathrm{i}\left(A_{1}+A_{2}+A_{3}\right)=0 ; \boldsymbol{F}_{\mathrm{M}}{ }^{(\mathrm{c})}(622)^{*}=+\mathrm{i}\left(A_{1}-A_{2}-A_{3}\right)=0
\end{gathered}
$$

In these conditions, the spins vectors $S_{\mathrm{j}}$ and $S_{\mathrm{j}+6}(\mathrm{j}=1-3)$ of $\mathrm{Tb}^{3+}\{24 \mathrm{c}\}$ and $\mathrm{Fe}^{3+}(24 \mathrm{~d})$ ions are coupled ferromagnetically and the symmetry operation $(\overline{1} \mid 0,0,0)$ is an inversion center. These significant properties related to magnetic symmetry involve that all the magnetic modes $A_{\mathrm{j}}$ are absent. This absence will be accompanied by the elimination of the modes $C_{\mathrm{j}}$. Consequently, the above crystallographic sites split into six magnetically inequivalent sublattices $C_{j}, C^{\prime}{ }_{j}$ and $D_{j}, D^{\prime}{ }_{j}$ with $(j=1-3)$ respectively as it is indicated on Table 1 . In each sublattice we have four ions which are equivalent under the symmetry operations: $(\overline{1} \mid 0,0,0)$ and $(1 \mid 1 / 2,1 / 2,1 / 2)$. The sublattices $C_{2}$ and $C_{3}$ are related to $C_{1}$ by a rotation of 120 and $240^{\circ}$ around the 3-fold symmetry [111] axis (also for $C^{\prime}{ }_{j}$ ); the same remarks can be made for the sublattices $D_{j}, D_{j}^{\prime} j(j=1-3)$. Contrary to previous spin rotation observed at $T_{\text {comp }}(260 \pm 5 \mathrm{~K})$ by mössbauer spectroscopy (Hong et al., 2004), no deviation from the colinearity along the easy axis [111] for the spins of the $\mathrm{Fe}^{3+}[16 \mathrm{a}]$ ions is evidenced around $T_{\text {comp }}(244 \pm 10 \mathrm{~K})$ (right of Fig. 9). In this $T$-region, this sublattice is described by one ferromagnetic configuration of the cubic magnetic modes $F$ and $F^{\prime}$ with the equality of the left of the equation (15). The

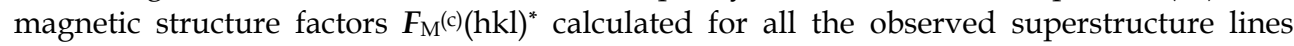
imply to know if we need both magnetic modes $F_{\mathrm{j}}(\mathrm{c})$ and $G_{\mathrm{j}}(\mathrm{c})$ in the description of the non collinear magnetic structures at low temperature

$$
F_{\mathrm{M}}{ }^{(\mathrm{c})}(100)^{*}=\sqrt{2} / 2\left(G_{1}-G_{2}\right)+\mathrm{i}\left[\sqrt{2} / 2\left(C_{1}+C_{2}\right)+A_{3}\right]
$$




$$
\begin{aligned}
& F_{\mathrm{M}}{ }^{(\mathrm{c})}(200)^{*}=-\boldsymbol{F}_{2}+\boldsymbol{F}_{3}+\mathrm{i} A_{1} \\
& \boldsymbol{F}_{\mathrm{M}}{ }^{(\mathrm{c})}(310)^{*}=\sqrt{2} / 2\left(-G_{1}+G_{2}\right)+\mathrm{i}\left[\sqrt{2} / 2\left(C_{1}-C_{2}\right)+A_{3}\right] \\
& F_{\mathrm{M}}{ }^{(\mathrm{c})}(411)^{*}=\sqrt{2} / 2\left(G_{2}-G_{3}\right)+\mathrm{i}\left[\sqrt{2} / 2\left(C_{2}+C_{3}\right)-A_{1}\right] \\
& F_{\mathrm{M}}{ }^{(\mathrm{c})}(330)^{*}=\sqrt{2} / 2\left(-G_{1}+G_{2}\right)+\mathrm{i}\left[\sqrt{2} / 2\left(C_{1}+C_{2}\right)-A_{3}\right] \\
& F_{\mathrm{M}}{ }^{(\mathrm{c})}(510)^{*}=\sqrt{2} / 2\left(-G_{1}-G_{2}\right)+\mathrm{i}\left[\sqrt{2} / 2\left(-C_{1}+C_{2}\right)+A_{3}\right] \\
& F_{\mathrm{M}}{ }^{(\mathrm{c})}(433)^{*}=\sqrt{2} / 2\left(-G_{2}+G_{3}\right)+\mathrm{i}\left[\sqrt{2} / 2\left(C_{2}+C_{3}\right)+A_{1}\right] \\
& F_{\mathrm{M}}{ }^{(\mathrm{c})}(530)^{*}=\sqrt{2} / 2\left(-G_{1}-G_{2}\right)+\mathrm{i}\left[\sqrt{2} / 2\left(-C_{1}-C_{2}\right)-A_{3}\right] \\
& \boldsymbol{F}_{\mathrm{M}}^{(\mathrm{c})}(600)^{*}=-\boldsymbol{F}_{2}+\boldsymbol{F}_{3}-\mathrm{i} A_{1} \\
& F_{\mathrm{M}}^{(\mathrm{c})}(442)^{*}=-\boldsymbol{F}_{2}+\boldsymbol{F}_{1}+\mathrm{i} A_{3}
\end{aligned}
$$

From these expressions, one can observe that both magnetic modes $F_{j}(\mathrm{c})$ and $G_{\mathrm{j}}(\mathrm{c})$ are necessary in the description of the non collinear structures of the $\mathrm{Tb}^{3+}$ ions. The absence of the small superstructure lines $(200)^{*}$ and $(600,442)^{*}$ above $13 \mathrm{~K}$ gives rise to the equality between the magnetic modes $F_{\mathrm{j}}$ (c) $(\mathrm{j}=1-3)$. It must be noted that the superstructure line $(510)^{*}$ appears at the same Bragg peak of the pure nuclear reflection (431) $\left(\theta=30.7^{\circ}\right)$. A magnetic contribution of the $\mathrm{RE}^{3+}$ ions exists for (431). We observe also a magnetic contribution for another reflection (541). It is very difficult to isolate only the magnetic contribution of these two reflections which are represented by their magnetic structure factors

$$
\begin{aligned}
& F_{\mathrm{M}}{ }^{(\mathrm{c})}(431)=\sqrt{2} / 2\left(-G_{2}+G_{3}\right)+\mathrm{i}\left[\sqrt{2} / 2\left(C_{2}-C_{3}\right)-A_{1}\right] \\
& F_{\mathrm{M}}{ }^{(\mathrm{c})}(541)=\sqrt{2} / 2\left(G_{1}+G_{3}\right)+\mathrm{i}\left[\sqrt{2} / 2\left(-C_{1}+C_{3}\right)-A_{2}\right]
\end{aligned}
$$

\subsection{Representation analysis of magnetic structures}

Bertaut (Bertaut, 1963, 1968, 1971, 1972) has created a group theory method called "Representation Analysis" which has been widely used in the last four decades by the Bertaut himself and by other researchers. The essential role is plaid by the "Basis Vectors of Irreductible Representations" of the paramagnetic space group Ia $\overline{3} \mathrm{~d}$ of TbIG and its highest subgroups.

\subsubsection{Representation analysis of la $\overline{3} d$}

The representation analysis of the cubic space group Ia $\overline{3} \mathrm{~d}$ was applied in the past (Bertaut et al., 1970; Tchéou et al., 1970a) in order to determine the spin configurations of the $\mathrm{Tb}^{3+}$ 
ions in TbIG. In the point group $O_{h}$ ten possible irreductible representations $\Gamma_{\mathrm{ig}}$ and $\Gamma_{\mathrm{iu}}(\mathrm{i}=$ 1-5) are present and listed usually on quantum mechanics text books (Flury Jr, 1980; Kahan, 1972). The subscripts $g$ and $u$ refer to irreductible representations which are even (gerade) and odd (ungerade) respectively under the inversion $I=(\overline{1} \mid 0,0,0)$. In their original works, two representations $\left(\Gamma_{4 \mathrm{~g}}=\mathrm{T}_{1 \mathrm{~g}}\right)$ and $\left(\Gamma_{5 \mathrm{~g}}=\mathrm{T}_{2 \mathrm{~g}}\right)$ were used. However, the coupling between the $\mathrm{RE}^{3+}$ in sites $\{24\}$ and the two iron ions $\mathrm{Fe}^{3+}$ in sites [16a] and (24d) has not been taken account in their study. The representation analysis of Ia $\overline{3} \mathrm{~d}$ has been developed later completely by the author (Lahoubi, 1986) in order to choose the common irreductible representation which could be able to represent both the Néel model at high temperature below $T_{\mathrm{N}}$ and the non collinear magnetic structures observed below $160 \mathrm{~K}$. For both $\mathrm{RE}^{3+}\{24 \mathrm{c}\}$ and $\mathrm{Fe}^{3+}(24 \mathrm{~d})$ sublattices, we need the even $\Gamma_{\mathrm{ig}}(\mathrm{i}=1-5)$ which appear only for $\mathrm{Fe}^{3+}[16 \mathrm{a}]$ sublattice. Using the precedent linear combinations of the spins of equations (12), (13) and (14), the sets of magnetic basis vectors of the three sublattices belonging to $\Gamma_{\mathrm{ig}}(\mathrm{i}=1-$ 5) which are formed by the functions $\Psi_{\operatorname{lm}}\left(1=1-d_{i g}, d_{i g}\right.$ the dimension of $\Gamma_{\text {ig }}$ and $m$ fixed $)$ are listed on Tables 2, 3 and 4. The letters $\mathrm{A}$ and $\mathrm{E}$ are assigned to one and two dimensional representations where $\left(\Psi_{11}\right)^{*}$ belongs to the complex conjugate representation with $\epsilon=$ $\{\exp (2 \pi i / 3)\}$. Due to the equation (13), it can be show that $\left(\Gamma_{5 \mathrm{~g}}=\mathrm{T}_{2 \mathrm{~g}}\right)$ is excluded and only $\left(\Gamma_{4 \mathrm{~g}}=\mathrm{T}_{1 \mathrm{~g}}\right)$ may be used to describe formally in a first approximation all magnetic structures.

\begin{tabular}{|c|c|c|c|}
\hline \multicolumn{4}{|c|}{$\Gamma_{1 \mathrm{~g}}=\mathrm{A}_{1 \mathrm{~g}}$} \\
\hline$\Gamma_{2 g}=A_{2 g}$ & $\Psi_{11}=G_{1 x}$ & $G_{3 z}$ & \\
\hline$\Gamma_{3 g}=E_{g}$ & $\begin{array}{l}\Psi_{11}=G_{1 x} \\
\Psi_{21}=-\epsilon(\end{array}$ & $+\epsilon^{2} G_{3 z}$ & \\
\hline$\Gamma_{4 \mathrm{~g}}=\mathrm{T}_{1 \mathrm{~g}}$ & $\begin{array}{l}\Psi_{11}=F_{1 x} \\
\Psi_{21}=F_{2 y} \\
\Psi_{31}=F_{3 z}\end{array}$ & $\begin{array}{l}\Psi_{12}=F_{2 x}+F_{3 x} \\
\Psi_{22}=F_{1 y}+F_{3 y} \\
\Psi_{32}=F_{1 z}+F_{2 z}\end{array}$ & $\begin{array}{l}\Psi_{13}=G_{2 z}+G_{3 y} \\
\Psi_{23}=G_{3 x}+G_{1 z} \\
\Psi_{33}=G_{1 y}+G_{2 x}\end{array}$ \\
\hline$\Gamma_{5 \mathrm{~g}}=\mathrm{T}_{2 \mathrm{~g}}$ & $\begin{array}{l}\Psi_{11}=F_{3 \mathrm{x}}- \\
\Psi_{21}=F_{1 \mathrm{y}}- \\
\Psi_{31}=F_{2 \mathrm{z}}-\end{array}$ & & $\begin{array}{l}\Psi_{13}=G_{3 y}-G_{2 z} \\
\Psi_{23}=G_{1 z}-G_{3 x} \\
\Psi_{33}=G_{2 x}-G_{1 y}\end{array}$ \\
\hline
\end{tabular}

Table 2. Basis vectors of the $\mathrm{RE}^{3+}$ in site $\{24 \mathrm{c}\}$ of Ia $\overline{3} \mathrm{~d}$

\begin{tabular}{|l|lll|}
\hline$\Gamma_{1 \mathrm{~g}}=\mathrm{A}_{1 \mathrm{~g}}$ & $\Psi_{11}=G_{1 \mathrm{x}}+G_{2 \mathrm{y}}+G_{3 \mathrm{z}}$ \\
\hline$\Gamma_{2 \mathrm{~g}}=\mathrm{A}_{2 \mathrm{~g}}$ & \multicolumn{3}{|l}{} \\
\hline$\Gamma_{3 \mathrm{~g}}=\mathrm{E}_{\mathrm{g}}$ & $\Psi_{11}=G_{1 \mathrm{x}}+\epsilon G_{2 \mathrm{y}}+\epsilon^{2} G_{3 \mathrm{z}}$ & \\
& $\Psi_{21}=+\epsilon\left(\Psi_{11}\right)^{*}$ & \\
\hline \multirow{5}{*}{$\Gamma_{4 \mathrm{~g}}=\mathrm{T}_{1 \mathrm{~g}}$} & $\Psi_{11}=F_{1 \mathrm{x}}$ & $\Psi_{12}=F_{2 \mathrm{x}}+F_{3 \mathrm{x}}$ & $\Psi_{13}=G_{3 \mathrm{y}}-G_{2 \mathrm{z}}$ \\
& $\Psi_{21}=F_{2 \mathrm{y}}$ & $\Psi_{22}=F_{1 \mathrm{y}}+F_{3 \mathrm{y}}$ & $\Psi_{23}=G_{1 \mathrm{z}}-G_{3 \mathrm{x}}$ \\
& $\Psi_{31}=F_{3 \mathrm{z}}$ & $\Psi_{32}=F_{1 \mathrm{z}}+F_{2 \mathrm{z}}$ & $\Psi_{33}=G_{2 \mathrm{x}}-G_{1 \mathrm{y}}$ \\
\hline \multirow{5}{*}{$\Gamma_{5 \mathrm{~g}}=\mathrm{T}_{2 \mathrm{~g}}$} & $\Psi_{11}=F_{3 \mathrm{x}}-F_{2 \mathrm{x}}$ & $\Psi_{12}=G_{3 \mathrm{y}}+G_{2 \mathrm{z}}$ & \\
& $\Psi_{21}=F_{1 \mathrm{y}}-F_{3 \mathrm{y}}$ & $\Psi_{22}=G_{1 \mathrm{z}}+G_{3 \mathrm{x}}$ & \\
& $\Psi_{31}=F_{2 \mathrm{z}}-F_{1 \mathrm{z}}$ & $\Psi_{32}=G_{2 \mathrm{x}}+G_{1 \mathrm{y}}$ & \\
\hline
\end{tabular}

Table 3. Basis vectors of the $\mathrm{Fe}^{3+}$ in site $[24 \mathrm{~d}]$ of Ia $\overline{3} \mathrm{~d}$ 


\begin{tabular}{|c|c|c|c|}
\hline$\Gamma_{1 \mathrm{~g}}=\mathrm{A}_{1 \mathrm{~g}}$ & \multicolumn{3}{|c|}{$\Psi_{11}=\left(A_{x}+C_{y}+G_{z}\right)-\left(G_{x}^{\prime}+A_{y}^{\prime}+C_{z}^{\prime}\right)$} \\
\hline$\Gamma_{2 g}=A_{2 g}$ & \multicolumn{3}{|c|}{$\Psi_{11}=\left(A_{x}+C_{y}+G_{z}\right)+\left(G_{x}^{\prime}+A_{y}^{\prime}+C_{z}^{\prime}\right)$} \\
\hline$\Gamma_{3 g}=E_{g}$ & \multicolumn{2}{|c|}{$\begin{array}{l}\Psi_{11}=A_{\mathrm{x}}+\epsilon C_{\mathrm{y}}+\epsilon^{2} G_{\mathrm{z}} \\
\Psi_{21}=-\left(A_{\mathrm{y}}^{\prime}+\epsilon G_{\mathrm{x}}^{\prime}+\epsilon^{2} C_{\mathrm{z}}^{\prime}\right)\end{array}$} & $\begin{array}{l}\Psi_{12}=-\left(A_{y}^{\prime}+\epsilon^{2} G_{x}^{\prime}+\epsilon C_{z}^{\prime}\right) \\
\Psi_{22}=A_{x}+\epsilon^{2} C_{y}+\epsilon G_{z}\end{array}$ \\
\hline$\Gamma_{4 \mathrm{~g}}=\mathrm{T}_{1 \mathrm{~g}}$ & $\begin{array}{l}\Psi_{11}=F_{x}+F_{x}^{\prime} \\
\Psi_{21}=F_{y}+F_{y}^{\prime} \\
\Psi_{31}=F_{z}+F_{z}^{\prime}\end{array}$ & $\begin{array}{l}\Psi_{12}=C_{z}+C_{y}^{\prime} \\
\Psi_{22}=G_{x}+G_{z}^{\prime} \\
\Psi_{32}=A_{y}+A_{x}^{\prime}\end{array}$ & $\begin{array}{l}\Psi_{13}=G_{y}+A^{\prime} \\
\Psi_{23}=A_{z}+C^{\prime} \\
\Psi_{33}=C_{x}+G_{y}^{\prime}\end{array}$ \\
\hline$\Gamma_{5 g}=T_{2 g}$ & $\begin{array}{l}\Psi_{11}=F_{\mathrm{x}}-F_{\mathrm{x}}^{\prime} \\
\Psi_{21}=F_{\mathrm{y}}-F_{\mathrm{y}}^{\prime} \\
\Psi_{31}=F_{\mathrm{z}}-F_{\mathrm{z}}^{\prime}\end{array}$ & $\begin{array}{l}\Psi_{12}=C_{z}-C_{y}^{\prime} \\
\Psi_{22}=G_{x}-G_{z}^{\prime} \\
\Psi_{32}=A_{y}-A_{x}^{\prime}\end{array}$ & $\begin{array}{l}\Psi_{13}=G_{y}-A_{z}^{\prime} \\
\Psi_{23}=A_{z}-C_{x}^{\prime} \\
\Psi_{33}=C_{x}-G_{y}^{\prime}\end{array}$ \\
\hline
\end{tabular}

Table 4. Basis vectors of the $\mathrm{Fe}^{3+}$ in site (16a) of $\mathrm{Ia} \overline{3} \mathrm{~d}$

In the high temperature region, the observed spectra which are well interpreted within the ferrimagnetic model of Néel are easily identified to the magnetic modes $\boldsymbol{F}_{\mathrm{j}}, \boldsymbol{F}$ and $\boldsymbol{F}^{\prime}$. At $T_{\text {comp }}$ $=243.5 \mathrm{~K}$ the mean exchange field acting on the $\mathrm{Tb}^{3+}$ ions by the iron sublattices is too strong ( $\sim 174 \mathrm{kOe})$ by comparison with the $\mathrm{Tb}^{3+}-\mathrm{Tb}^{3+}$ exchange field $(\sim 8 \mathrm{kOe})$ (Lahoubi, 1986); this last coupling beetwen the Tb3+ ions will be not able to decouple at low temperature the two sublattices. This remarkable property excludes permanently the intervention of the three-dimensional irreductible representation $\left(\Gamma_{5 \mathrm{~g}}=\mathrm{T}_{2 \mathrm{~g}}\right)$ where the magnetic modes of the rare earth sublattice are along the $<0 \overline{1} 1>$ directions. Using the basis vectors of $\left(\Gamma_{4 \mathrm{~g}}=\mathrm{T}_{1 \mathrm{~g}}\right)$, we present in Fig. 10 the four cubic models of "double umbrella" of type II (Lahoubi, 1986) in the irreductible representation $\left(\Gamma_{4 \mathrm{~g}}=\mathrm{T}_{1 \mathrm{~g}}\right)$ of Ia $\overline{3} \mathrm{~d}$

"Double umbrella of type II" : $S_{1}=+S_{7}=(\mathrm{f}, \mathrm{F}+\mathrm{G}, \mathrm{F}+\mathrm{G}) ; S_{4}=+S_{10}=(\mathrm{f}, \mathrm{F}-\mathrm{G}, \mathrm{F}-\mathrm{G})$; c.p. (29)
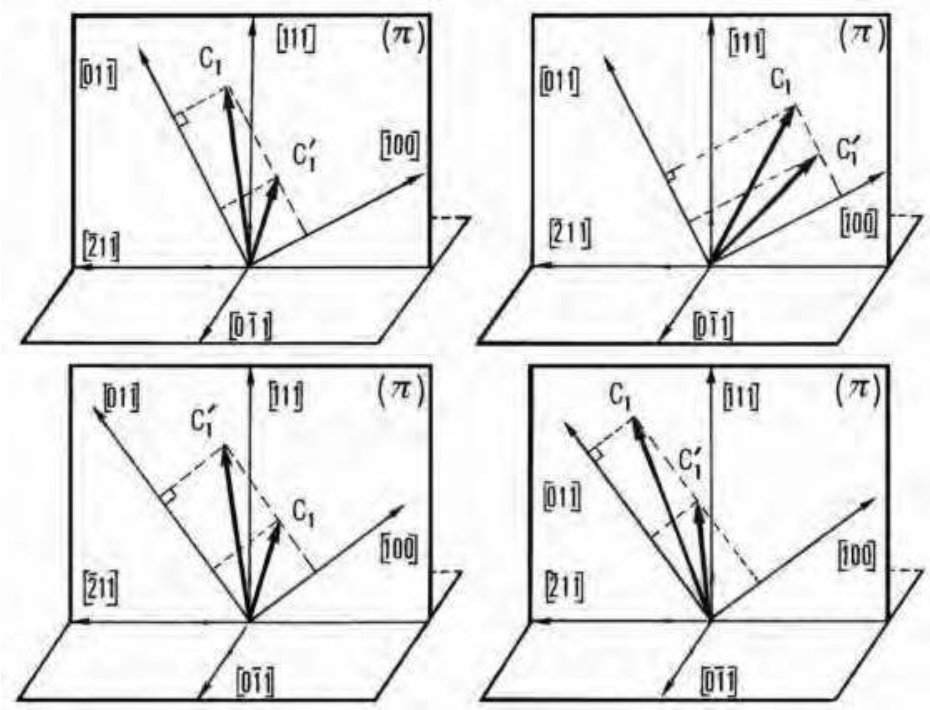

Fig. 10. Four cubic "double umbrella" models of type II for $\left(\Gamma_{4 \mathrm{~g}}=\mathrm{T}_{\mathrm{gg}}\right)$ of Ia $\overline{3} \mathrm{~d}$. 
In these four models, the angles and the modulus of the moments $m_{1}$ and $m_{1}^{\prime}$ are different. They must to respect some requirements: the components of the moments $m_{1}, m_{1}^{\prime}$ along the cubic axis [100] are necessary equals; also for the components of the moments $m_{2}, m_{2}^{\prime}$ and $m_{3}, m_{3}^{\prime}$ respectively along [010] and [001]. The components of the moment $m_{1}$ along the cubic axes [010] and [001] must be equals; also for $\boldsymbol{m}_{2}$ and $\boldsymbol{m}_{2}{ }_{2}$ along [100] and [001]; also for $m_{3}$ and $m_{3}^{\prime}$ along [100] and [010]. The first refinements at $4.2 \mathrm{~K}$ (with $m_{\mathrm{a}}=m_{\mathrm{d}}=5 \mu_{\mathrm{B}}$ ) lead to values of the moment $m_{1}^{\prime}\left(\sim 10 \mu_{\mathrm{B}}\right)$, i.e., above the free $\mathrm{Tb}^{3+}$ ion value $\left(9 \mu_{\mathrm{B}}\right)$. The reason of this discrepancy is associated to the deviation of the cubic description which imply a rhombohedral distortion observed on powder sample by X-ray diffraction at $6 \mathrm{~K}$ (Bertaut et al., 1970, Sayetat, 1974, 1986 and refs. herein) and neutron diffractions at $5 \mathrm{~K}$ (Hock et al., 1990) where two subgroups of Ia $\overline{3}$ d have been proposed respectively: $R \overline{3} c$ and $R \overline{3}$.

\subsubsection{Representation analysis of $\mathrm{R} \overline{3} \mathrm{C}$}

A detailed description of the representation analysis of the subgroup $R \overline{3} c$ is presented here. According to the earlier precise X-ray diffraction measurements of the rhombohedral distortions carried out on single crystals of the terbium-yttrium iron garnet system $\mathrm{Tb}_{\mathrm{x}} \mathrm{Y}_{3-\mathrm{x}} \mathrm{Fe}_{5} \mathrm{O}_{12}$ with $0 \leq \mathrm{x} \leq 3$ (hereafter $\mathrm{Tb}_{\mathrm{x}} \mathrm{Y}_{3-\mathrm{x}} \mathrm{IG}$ ) (Levitin et al., 1983), the choice of the subgroup $\mathrm{R} \overline{3} \mathrm{c}$ seems more appropriate. This choice will be confirmed later by our high field magnetization measurements and the use of the method of "the symmetry lowering device" (Bertaut, 1981) which is connected with representation analysis of Bertaut (Bertaut, 1968, 1971, 1972). From the International Tables (Hahn, 1983), the Bravais lattice of the crystallographic space group $R \overline{3} \mathrm{c}-\left(\mathrm{D}_{3 \mathrm{~d}}^{6}\right)$ No. 167 is defined in the system of the rhombohedral directions [ $\overline{1} 11],[1 \overline{1} 1],[11 \overline{1}]$ with the three fundamental vectors: $A_{1}, A_{2}, A_{3}$ with the same parameter $A_{\mathrm{Rh}}$ and an angle $\mathrm{a}_{\mathrm{Rh}} \# 90^{\circ}$ and $<120^{\circ}$ respectively along the unit vectors $\left.g_{\mathrm{j}}, \mathrm{j}=1-3\right)$. There are related to the cubic axes by unit vectors $\{i, j, k\}$

$$
\begin{gathered}
g_{1}=1 / \sqrt{3}(-i+j+k) ; g_{2}=1 / \sqrt{3}(+i-j+k) ; g_{3}=1 / \sqrt{3}(+i+j-k) \\
X=y+z ; Y=x+z ; Z=x+y
\end{gathered}
$$

The correspondence between the ion positions in the two space groups Ia $\overline{3} \mathrm{~d}$ and $\mathrm{R} \overline{\mathrm{3}} \mathrm{c}$ is reported on Table 5. For TbIG, the values of the parameters found at $6.75 \mathrm{~K}$ (Sayetat, 1974, 1986) are: $A_{\mathrm{Rh}}=10.7430 \AA ; \mathrm{a}_{\mathrm{Rh}}=109^{\circ} 24^{\prime} 40^{\prime \prime}$. The rhombohedral unit cell contains only the half atoms of the cubic unit cell. In order to use the representation analysis to determine the magnetic basis vectors, we choose the following generators of the space group $\mathrm{R} \overline{3} \mathrm{c}$ : the identity $E=(1 \mid 0,0,0)$, the inversion $I=(\overline{1} \mid 0,0,0)$, a ternary axis $3=(3 \mid 0,0,0)$ and a diagonal binary axis $2_{d}=(2 x \bar{Y} \mid 1 / 2,1 / 2,1 / 2)$. This axis is perpendicular to the glide plane $c=I .2_{d}$ of the symbol $\mathrm{R} \overline{3} \mathrm{c}$. The wave vector being $k=0$, the six irreductible representations of the space group $R \overline{3} c$ are those of the point group $D_{3 d}, \Gamma_{j g}$ and $\Gamma_{j u}$ with $j=1-3$. The previous three-dimensional irreductible representation $\left(\Gamma_{4 \mathrm{~g}}=\mathrm{T}_{1 \mathrm{~g}}\right)$ of $O_{h}$ is reduced to: $\Gamma_{2 \mathrm{~g}}=\mathrm{A}_{2 \mathrm{~g}}+\mathrm{E}_{\mathrm{g}}$. Only the one-dimensional irreductible representation will be chosen in our study (the twodimensional irreductible representation $E_{\mathrm{g}}$ being complex, she is not considered). It appears that the previous linear combinations of the spin vectors $F, G, C$ and $A$ are not in reality 


\begin{tabular}{|c|c|c|c|c|c|c|}
\hline & \multicolumn{3}{|c|}{ Ia $\overline{3} \mathrm{~d}$} & \multicolumn{3}{|r|}{$\mathrm{R} \overline{3} \mathrm{c}$} \\
\hline Ions & \multicolumn{2}{|c|}{ Sites Symmetry } & Positions & \multicolumn{2}{|c|}{ Sites Symmetry } & \multirow{2}{*}{$\begin{array}{c}\text { Positions } \\
\pm(X, 1 / 2-X, 1 / 4) \\
X \approx 3 / 8 ; \text { c.p. } \\
\pm(X, 1 / 2-X, 1 / 4) \\
X \approx 7 / 8 ; \text { c.p. }\end{array}$} \\
\hline $\mathrm{RE}^{3+}$ & $24 c$ & 222 & $\begin{array}{l} \pm(1 / 8,0,1 / 4) ; \text { c.p. } \\
\pm(3 / 8,0,3 / 4) ; \text { c.p. }\end{array}$ & $\begin{array}{l}6 \mathrm{e} \\
6 \mathrm{e}^{\prime}\end{array}$ & $\begin{array}{l}2 \\
2\end{array}$ & \\
\hline $\mathrm{Fe}^{3+}$ & $24 d$ & 4 & $\begin{array}{l} \pm(3 / 8,0,1 / 4) ; \text { c.p. } \\
\pm(1 / 8,0,3 / 4) ; \text { c.p. }\end{array}$ & $12 f$ & 1 & $\begin{array}{c} \pm(X, Y, Z) ; \text { c.p. } \\
\pm(Y+1 / 2, X+1 / 2, Z+1 / 2) ; \\
\text { c.p. } \\
X \approx 5 / 8, Y \approx 3 / 8, Z \approx 1 / 4\end{array}$ \\
\hline $\mathrm{Fe}^{3+}$ & $16 a$ & $\overline{3}$ & $\begin{array}{c}0,0,0 ; 1 / 4,1 / 4,1 / 4 \\
0,1 / 2,1 / 2 ; \text { c.p. } \\
\text { 1/4,3/4,3/4; c.p. }\end{array}$ & $\begin{array}{l}2 b \\
6 d\end{array}$ & $\begin{array}{l}\overline{3} \\
\overline{1}\end{array}$ & $\begin{array}{c}0,0,0 ; 1 / 2,1 / 2,1 / 2 \\
0,1 / 2,1 / 2 ; \text { c.p. } \\
1 / 2,0,0 ; \text { c.p. }\end{array}$ \\
\hline $\mathrm{O}^{2-}$ & $96 \mathrm{~h}$ & 1 & & $12 f$ & 1 & $\mathrm{O}_{\mathrm{I}} \mathrm{O}_{\text {II }} \mathrm{O}_{\text {III }} \mathrm{O}_{\mathrm{IV}}$ \\
\hline
\end{tabular}

Table 5. Correspondence between the positions of the ions in Ia $\overline{3} \mathrm{~d}$ and $\mathrm{R} \overline{3} \mathrm{C}$

adapted to describe the magnetic structures of the three magnetic ions. For the $\mathrm{RE}^{3+}$ ions, the preceding magnetically inequivalent sublattices $C_{j}$ and $C^{\prime}{ }_{j}(j=1-3)$ become crystallographic inequivalent sites $6 \mathrm{e}$ and $6 \mathrm{e}^{\prime}$; they are described in the rhombohedral axis $\mathrm{X}, \mathrm{Y}, \mathrm{Z}$ by a new linear combination for the ferromagnetic mode $f_{\mathrm{j}}=S_{\mathrm{j}}+S_{\mathrm{j}+6}(\mathrm{j}=1-3)$. Concerning the iron ions sublattices $D_{j}$ and $D_{j}^{\prime}$ of the $24 \mathrm{~d}$ site, they will be associated to a new $12 \mathrm{f}$ site where the basis vectors are described with the ferromagnetic mode $V_{\mathrm{j}}=S_{\mathrm{j}}+S_{\mathrm{j}+6}(\mathrm{j}=1-3)$. The associated basis vectors of $\left(\Gamma_{2 \mathrm{~g}}=\mathrm{A}_{2 \mathrm{~g}}\right)$ are presented here on Table 6. A new combination of these basis vectors is proposed and four modified double umbrella models are presented for the six sublattices $C_{j}$ and $C_{j}^{\prime}$ on Table 7 . In this description, the first part (f $n$ ) of the moment $m_{j}$ represents the collinear ferromagnetic mode of the component along the [111] direction.

\begin{tabular}{|c|c|c|}
\hline & & $\mathrm{R} \overline{3} \mathrm{c}$ \\
\hline Ions & Sites & Basis vectors \\
\hline $\mathrm{RE}^{3+}$ & $\begin{array}{l}6 e \\
6 e^{\prime}\end{array}$ & $\begin{array}{c}\Psi_{11}(\mathrm{I})=f_{1 X}+f_{2 Y}+f_{3 Z} \\
\Psi_{11}(\mathrm{II})=f_{1 Y}+f_{1 \mathrm{Z}}+f_{2 Z}+f_{2 X}+f_{3 \mathrm{X}}+f_{3 \mathrm{Y}} \\
\Psi_{11}(\mathrm{IV})=f_{4 \mathrm{X}}+f_{5 \mathrm{Y}}+f_{6 \mathrm{Z}} \\
\Psi_{11}(\mathrm{~V})=f_{4 \mathrm{Y}}+f_{4 \mathrm{Z}}+f_{5 \mathrm{Z}}+f_{5 \mathrm{X}}+f_{6 \mathrm{X}}+f_{6 \mathrm{Y}}\end{array}$ \\
\hline $\mathrm{Fe}^{3+}$ & $12 \mathrm{f}$ & $\begin{array}{l}\Psi_{11}(\mathrm{I})=V_{1 X}+V_{2 Y}+V_{3 Z}+V_{4 X}+V_{5 Y}+V_{6 Z} \\
\Psi_{11}(\mathrm{II})=V_{2 X}+V_{3 Y}+V_{1 Z}+V_{6 X}+V_{4 Y}+V_{5 Z} \\
\Psi_{11}(\mathrm{III})=V_{3 X}+V_{1 Y}+V_{2 Z}+V_{5 X}+V_{6 Y}+V_{4 Z}\end{array}$ \\
\hline $\mathrm{Fe}^{3+}$ & $\begin{array}{l}2 b \\
6 d\end{array}$ & $\begin{array}{l}\Psi_{11}(\mathrm{I})=\left(S_{1}+S_{5}\right) \mathrm{x}+\left(S_{1}+S_{5}\right) \mathrm{Y}+\left(S_{1}+S_{5}\right) \mathrm{Z} \\
\Psi_{11}(\mathrm{II})=\left(S_{2}+S_{6}\right) \mathrm{x}+\left(S_{3}+S_{7}\right) \mathrm{Y}+\left(S_{4}+S_{8}\right) \mathrm{z} \\
\Psi_{11}(\mathrm{III})=\left(S_{3}+S_{8}\right) \mathrm{x}+\left(S_{4}+S_{6}\right) \mathrm{Y}+\left(S_{2}+S_{7}\right) \mathrm{Z} \\
\Psi_{11}(\mathrm{IV})=\left(S_{4}+S_{7}\right) \mathrm{x}+\left(S_{2}+S_{8}\right) \mathrm{Y}+\left(S_{3}+S_{6}\right) \mathrm{Z}\end{array}$ \\
\hline
\end{tabular}

Table 6. Basis vectors of ions in the irreductible representation $A_{2 g}$ of $R \overline{3} c$ 


\begin{tabular}{|c|c|}
\hline $\begin{array}{c}\text { Four } \mathrm{A}_{2 \mathrm{~g}} \text { models in } \mathrm{R} \overline{3} \mathrm{c} \\
\text { with } \mathrm{f} \neq \mathrm{f}^{\prime} \text { and } \mathrm{a} \neq \mathrm{a}^{\prime}\end{array}$ & $\begin{array}{c}\text { New model for TbIG with } \mathrm{f} \neq \mathrm{f}^{\prime} \text { and } \mathrm{a}^{\prime} \approx \mathrm{a}-\varepsilon \\
(\varepsilon \rightarrow 0 \text { at } \mathrm{T}>5 \mathrm{~K})\end{array}$ \\
\hline$(6 \mathrm{e}): \mathrm{C}_{\mathrm{j}}: S_{\mathrm{j}}=S_{\mathrm{j}+6}=\mathrm{f} n \pm \mathrm{ag}_{\mathrm{j}}$ & $\mathrm{C}_{1}: \boldsymbol{m}_{1}=S_{1}=S_{7}=(\mathrm{f}-\mathrm{a} / 3) n-(2 \sqrt{2} / 3) \mathrm{a} p_{1}$ \\
\hline$\left(6 \mathrm{e}^{\prime}\right): \mathrm{C}_{\mathrm{j}}^{\prime}: S^{\prime}{ }_{\mathrm{j}}=S^{\prime}{ }_{\mathrm{j}+6}=\mathrm{f}^{\prime} n \pm \mathrm{a}^{\prime} g_{\mathrm{j}}$ & $\mathrm{C}_{1}^{\prime}: \boldsymbol{m}^{\prime}{ }_{1}=S_{4}=S_{10}=\left(\mathrm{f}^{\prime}+\mathrm{a}^{\prime} / 3\right) n+(2 \sqrt{2} / 3) \mathrm{a}^{\prime} \boldsymbol{p}_{1}$ \\
\hline
\end{tabular}

Table 7. Four rhombohedral models in $A_{2 g}$ of $R \overline{3} c$ and new model for TbIG (Lahoubi, 2012)

The second part $\left( \pm \mathrm{a} g_{\mathrm{j}}\right)$ represents the non collinear antiferromagnetic modes of the components of the moment $m_{\mathrm{j}}$ along the three rhombohedral axes $\{[\overline{1} 11],[1 \overline{1} 1],[11 \overline{1}]\}$. Some requirements from the previous "cubic description" are now ignored in the "rhombohedral description": the axis [100] and equivalent directions cease to be principal axes. In the four models of non collinear arrangements for the $\mathrm{RE}^{3+}$ ions around the ternary axis [111], the sublattices $C_{j}, C_{j}^{\prime}$ are situated in the three glide planes c, c. 3 and c. $3^{2}$ of the subgroup $R \overline{3}$ c: each plane containing [111] (unit vector $n$ ) and one of the rhombohedral directions $\{[111],[1 \overline{1} 1]$, $[11 \overline{1}]\}$ represented by the unit vectors $g_{j}, j=1-3$. In this condition, we have: $\mathrm{c}=\left(n, g_{3}\right) ; \mathrm{c} .3=(n$, $\left.g_{1}\right)$ and c.32 $=\left(n, g_{2}\right)$ (Fig. 11a). Furthermore, the projection on the plane (111) of the rhombohedral direction [ $\overline{1} 11]\left(g_{1}\right)$ for example, is equivalent to the low symmetry axis [ $\left.\overline{2} 11\right]$ (with the unit vector $p_{1}$ ); the local axis $[0 \overline{1} 1](W)$ is also chosen. If one takes into account the smallness superstructure lines $(200)^{*}$ and $(600,442)^{*}$ at $5 \mathrm{~K}$ (D1B), new parameters are found for $C_{1}\left(m_{1}, \theta_{1}, \phi_{1}\right)$ and $C_{1}^{\prime}\left(m_{1}^{\prime}, \theta_{1}^{\prime}, \phi_{1}^{\prime}\right)$ sites (Lahoubi, 2012) (Fig. 11b). The moments of $C_{1}$ and $C_{1}^{\prime}$ are drawed in the (п) plane which corresponds to glide plane c.3: this plane remains a principal plane of the magnetic tensor $\tilde{g}$ of the earlier "cubic description". A good reliability factor $R$ of the order of $6.7 \%$ is found for a refinement based on all the reflections and the method of validation of the magnetic structures (Wills, 2007 and refs. herein):
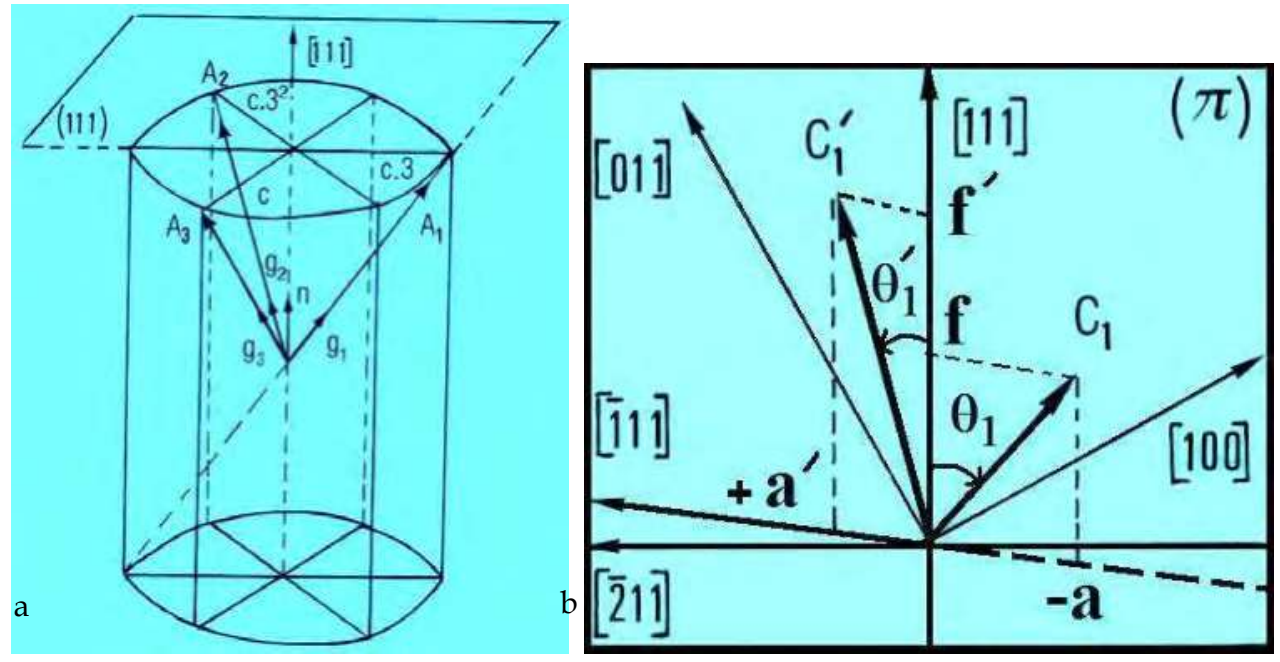

Fig. 11. a. The three glide planes of $R \overline{3} c, b$. New model for $C_{1}$ and $C^{\prime}{ }_{1}$ at $5 K$ (D1B) 

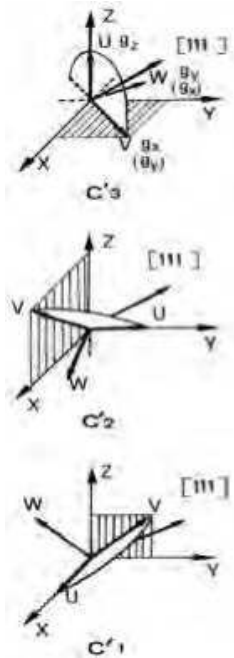

a
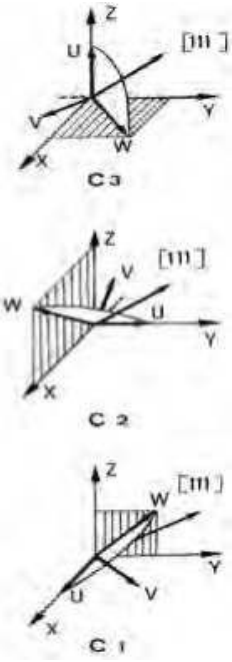

$\mathrm{b}$

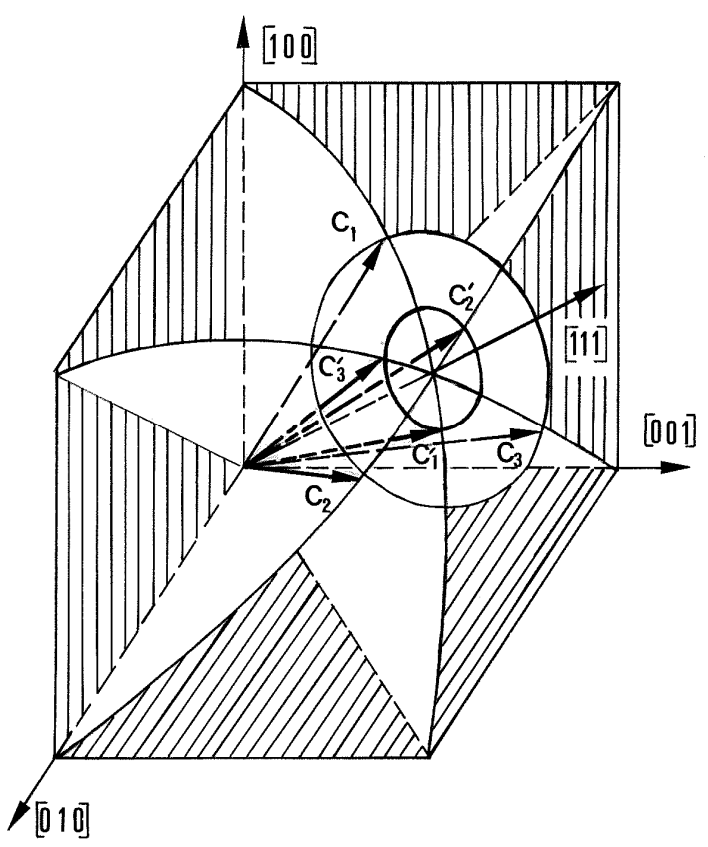

Fig. 12. a. Local axes of the D2(222) symmetry, b. Novel "double umbrella" at $5 \mathrm{~K}$

$$
\begin{aligned}
& C_{1}: m_{1}=8.07 \mu_{\mathrm{B}} ; \theta_{1}=32^{\circ} ; \phi_{1}=180^{\circ} \\
& C_{1}^{\prime}: m_{1}^{\prime}=8.90 \mu_{\mathrm{B}} ; \theta_{1}^{\prime}=27^{\circ} ; \phi_{1}^{\prime}=0^{\circ}
\end{aligned}
$$

where, $\phi_{1}$ and $\phi_{1}^{\prime}$ are the angles from $p_{1}$ in the (111) plane and $\varepsilon=0.20 \mu_{\mathrm{B}}$; with $\delta\left(M_{\mathrm{S}}\right)<111>=$ $M_{\mathrm{S}}{ }^{\mathrm{cal}}-M_{\mathrm{S}}$ mes $=0.03 \mu_{\mathrm{B}} / \mathrm{mol}$. For a better presentation one can show the novel "double umbrella "(Fig. 12b) in the local axes of the D2(222) symmetry (Fig. 12a). These results are in good agreement with our recent high magnetic field magnetizations performed at $4.2 \mathrm{~K}$ (Lahoubi, 2012) where a third low critical field $H_{\mathrm{c} 0}$ (Fig. 13) is observed along the <100> direction and added to the previous $H_{\mathrm{c} 1}$ and $H_{\mathrm{c} 2}$ (Lahoubi et al., 1984). They confirm unambiguously the presence of the three magnetic glide planes $c^{\prime}$ of the symbol $R \overline{3} c^{\prime}$. The earlier results at $5 \mathrm{~K}$ described in the subgroup $\mathrm{R} \overline{3}$ (Hock et al., 1990) lead to values of the components $m_{1 \mathrm{x}}$ and $m_{1 \mathrm{z}}^{\prime}$ above the value $\left(9 \mu_{\mathrm{B}}\right)$ of the free $\mathrm{Tb}^{3+}$ ion.

\section{Temperature evolution of the double umbrella structure}

The parameters for the sites $C_{1}\left(m_{1}, \theta_{1}, \phi_{1}=180^{\circ}\right)$ and $C_{1}^{\prime}\left(m^{\prime}{ }_{1}, \theta^{\prime}{ }_{1}, \phi_{1}^{\prime}{ }_{1}=0^{\circ}\right)$ are refined with the same model found at $5 \mathrm{~K}$ with the condition $\varepsilon \rightarrow 0\left(m_{1} \perp=-m^{\prime}{ }_{1} \perp\right)$ due to the absence of the superstructure lines $(200)^{*}$ and $(600,442)^{*}$ above $13 \mathrm{~K}$ (D1B) (Fig. 4). The magnetic moments $m_{\mathrm{a}}$ and $m_{\mathrm{d}}$ of the iron sublattices were not concerned by the refinements for all reflections of the patterns and the observed values found by N.M.R. experiments (Gonano et al., 1967) are used. Good agreement is obtained with the reliability factors $R$ varying between 6 and $10 \%$ in the $4.2-283 \mathrm{~K}$ temperature range. 


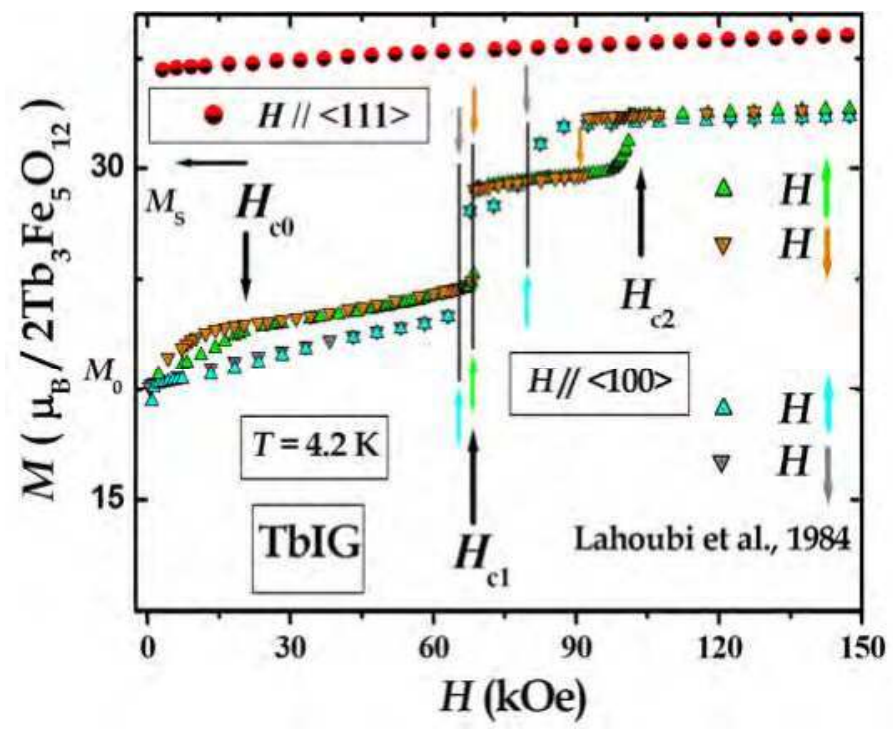

Fig. 13. $M_{\mathrm{T}}(H)$ versus $H$ at $4.2 \mathrm{~K}$ along the $<111>$ and $<100>$ directions (Lahoubi, 2012)

The equation (5) in the section 3, permit us to deduce the magnetic intensities $I_{M}$ by assuming negligible the $T$-variations of $I_{\mathrm{N}}$ with a rather good precision for the reflections (hkl) which have a great magnetic contribution such as $(211),(321),(521)$ and $(532,611)$ where the ratio $\left(I_{\mathrm{M}} / I_{\mathrm{N}}\right)_{\text {cal }}$ is equal respectively to: 200, 20, 4 and 2. Consequently, the high magnetically reflections with a small nuclear contribution are only (211) and (321). The thermal variations of these two magnetic reflections which are responsible of the collinear ferrimagnetic ordering are reported in Fig. 14. They appear at $T_{\mathrm{N}}$ and present a first increase below $160 \mathrm{~K}$ with a second rapid increase at $68 \mathrm{~K}$. Different and complex temperature dependences are observed for the reflections (220) and (440). At first, the values of $\left(I_{\mathrm{M}}\right)_{\mathrm{cal}}$ are higher than those observed for $\left(I_{\mathrm{M}}\right)_{\mathrm{obs}}$. These two reflections increase simultaneously between 4.2 and $160 \mathrm{~K}$ and present an inflexion point near $68 \mathrm{~K}$. Above $160 \mathrm{~K}$, they tend to a plateau until room temperature after which they decrease progressively and reach zero at $T_{\mathrm{N}}$. The possible explanation of this characteristic behavior seems to be related to the magnetic contribution of the irons in the octahedral site [16a] to the total intensity $I$, which is not the case for the reflections (211) and (321). Another good agreement between $\left(I_{\mathrm{M}}\right)_{\mathrm{obs}}$ and $\left(I_{\mathrm{M}}\right)_{\text {cal }}$ is found in the thermal variations of the superstructure lines $(310)^{*},(110)^{*},(411,330)^{*}$ and $(530,433)^{*}$ plotted in Fig. 15 where a rapid variation is observed at $68 \mathrm{~K}$. Two distinct magnetic behaviors separated by the specific temperature $160 \mathrm{~K}$ are clearly evidenced.

The refined values of the parameters $\left(m_{\mathrm{j}}, m_{\mathrm{j}}^{\prime}\right)$ and $\left(\theta_{\mathrm{j}}, \theta_{\mathrm{j}}^{\prime}\right)$ listed on Table 8 in the $4.2-283 \mathrm{~K}$ temperature range lead to a good agreement between $M_{S}{ }^{\text {cal }}$ and $M_{S}{ }^{\text {mes }}$. During the refinement at $109 \pm 2 \mathrm{~K}$, two different results related to the set $\{a, b\}$ are found and lead to identical values of $M_{\mathrm{S}} \mathrm{cal}$ and reliability factor $R$. The same feature is observed for the set $\{c$, d) at $127 \pm 5 \mathrm{~K}$. We observe in the thermal variations of the parameters $\left(m_{\mathrm{j}}, m_{\mathrm{j}}^{\prime}\right)$ and $\left(\theta_{\mathrm{j}}, \theta_{\mathrm{j}}^{\prime}\right)$ plotted in Fig. 16 a broad variation between $54 \mathrm{~K}$ and $80 \mathrm{~K}$ which disappears beyond $160 \mathrm{~K}$. 

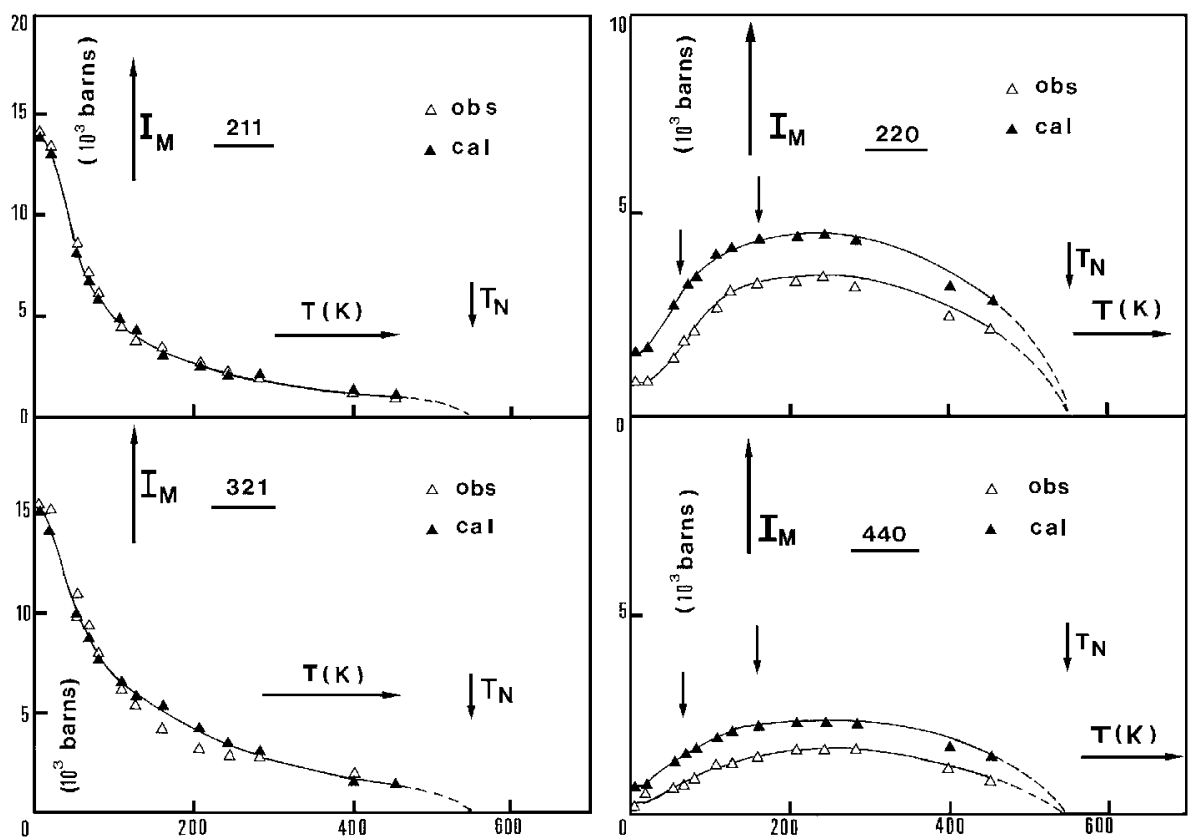

Fig. 14. Thermal variations of $\left(I_{\mathrm{M}}\right)_{\mathrm{obs}}$ and $\left(I_{\mathrm{M}}\right)_{\mathrm{cal}}$ for the reflections (211), (321), (220) and (440)
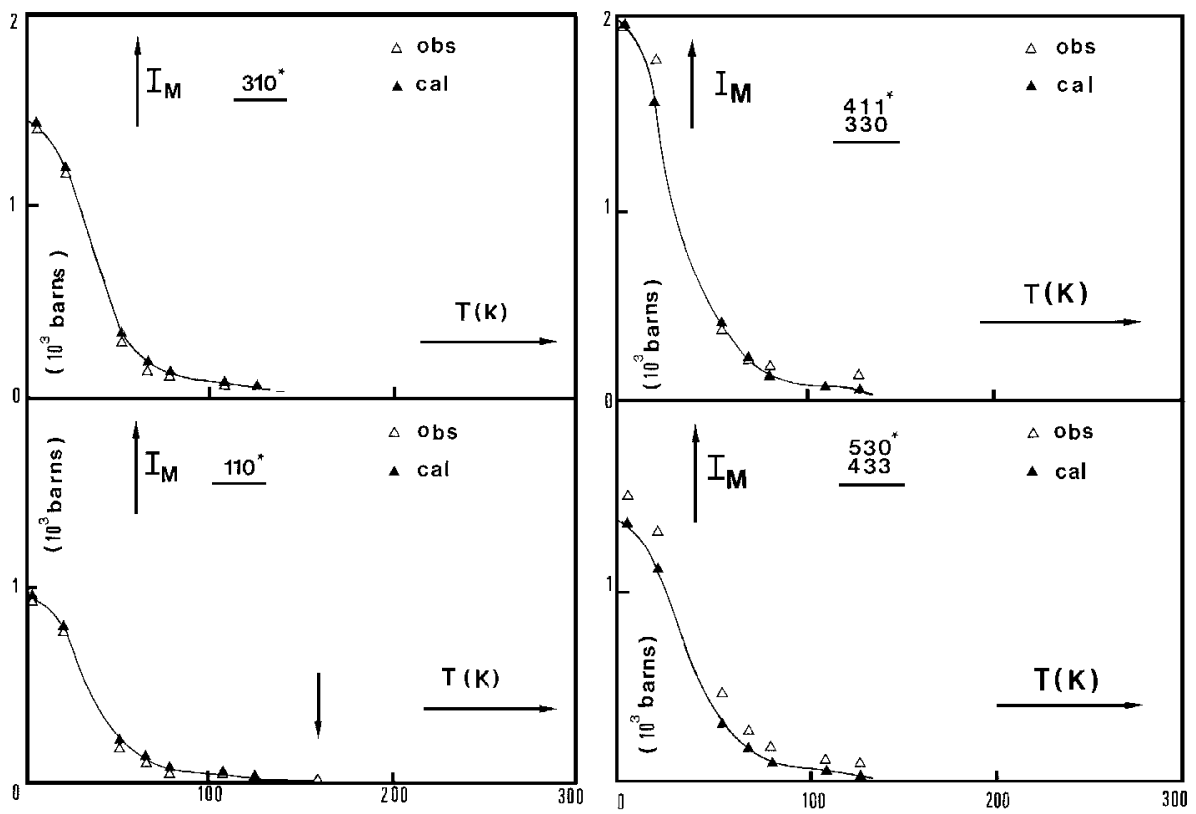

Fig. 15. Thermal variations of $\left(I_{\mathrm{M}}\right)_{\mathrm{obs}}$ and $\left(I_{\mathrm{M}}\right)_{\mathrm{cal}}$ for the superstructure lines $(310)^{*},(110)^{*}$, $(411,330)^{*}$ and $(530,433)^{*}$ 


\begin{tabular}{|c|c|c|c|c|c|c|c|c|}
\hline & \multicolumn{2}{|c|}{ Sites $C_{1} ; C_{1}^{\prime}$} & \multicolumn{3}{|l|}{$M_{\mathrm{S}}^{\mathrm{cal}}$} & \multicolumn{3}{|c|}{$M_{\mathrm{S}}{ }^{\mathrm{mes}} \quad\left(\mu_{\mathrm{B}} / \mathrm{mol}\right)$} \\
\hline$T(\mathrm{~K})$ & $\begin{array}{l}m_{1}\left(\mu_{\mathrm{B}}\right) \\
m_{1}^{\prime}\left(\mu_{\mathrm{B}}\right)\end{array}$ & $\begin{array}{c}\theta_{1}\left(^{\circ}\right) \\
\left.\theta_{1}^{\prime} 1^{\circ}\right) \\
\end{array}$ & [111] & [110] & [100] & [111] & [110] & [100] \\
\hline 4.2 & $\begin{array}{l}8.18 \\
8.90\end{array}$ & $\begin{array}{l}30.79 \\
28.07\end{array}$ & 34.64 & 28.28 & 20.00 & 34.53 & 28.35 & 20.17 \\
\hline 5 & $\begin{array}{l}8.07 \\
8.99\end{array}$ & $\begin{array}{l}32.00 \\
27.00 \\
\end{array}$ & 34.56 & 28.22 & 19.95 & $"$ & " & " \\
\hline 20 & $\begin{array}{l}7.49 \\
8.77\end{array}$ & $\begin{array}{l}30.11 \\
25.39\end{array}$ & 33.21 & 27.12 & 19.18 & 33.34 & 27.21 & 19.56 \\
\hline 54 & $\begin{array}{l}4.79 \\
6.27 \\
\end{array}$ & $\begin{array}{l}22.57 \\
17.03 \\
\end{array}$ & 21.32 & 17.41 & 12.31 & 21.24 & 17.24 & 12.80 \\
\hline 68 & $\begin{array}{l}4.23 \\
5.21\end{array}$ & $\begin{array}{l}19.57 \\
15.76 \\
\end{array}$ & 17.10 & 13.97 & 9.87 & 17.01 & 13.44 & 10.05 \\
\hline 80 & $\begin{array}{l}3.57 \\
4.72 \\
\end{array}$ & $\begin{array}{l}16.72 \\
12.56 \\
\end{array}$ & 14.25 & 11.63 & 8.23 & 13.97 & 11.70 & 8.38 \\
\hline $\begin{array}{l}109 \\
\pm 2\end{array}$ & $\begin{array}{c}2.76^{\mathrm{a}} \\
3.79^{-1.78^{\mathrm{b}}} \\
3.78^{2} \\
\end{array}$ & $\begin{array}{l}15.04 \\
10.86 \\
15.23 \\
11.20 \\
\end{array}$ & 9.48 & 7.74 & 5.47 & 8.78 & 7.20 & 5.26 \\
\hline $\begin{array}{l}127 \\
\pm 5\end{array}$ & $\begin{array}{c}2.59 \mathrm{c} \\
3.12 \\
2.71^{\mathrm{d}} \\
3.00 \\
\end{array}$ & $\begin{array}{l}14.94 \\
12.30 \\
14.52 \\
13.08 \\
\end{array}$ & 7.13 & 5.82 & 4.12 & 6.52 & 5.40 & 3.88 \\
\hline 160 & $\begin{array}{l}2.30 \\
2.31\end{array}$ & $\begin{array}{l}0.11 \\
0.00 \\
\end{array}$ & 4.65 & 3.80 & 2.68 & 4.61 & 3.76 & 2.66 \\
\hline $\begin{array}{l}208 \\
\pm 2 \\
\end{array}$ & $\begin{array}{l}1.74(3) \\
1.75(7) \\
\end{array}$ & $\begin{array}{l}0.05 \\
0.00 \\
\end{array}$ & 1.92 & 1.56 & 1.11 & 1.97 & 1.36 & 1.12 \\
\hline $\begin{array}{c}244 \\
\pm 10 \\
\end{array}$ & $\begin{array}{l}1.34(4) \\
1.35(8)\end{array}$ & $\begin{array}{l}0.08 \\
0.00\end{array}$ & 0 & 0 & 0 & 0 & 0 & 0 \\
\hline 283 & $\begin{array}{l}1.15 \\
1.15 \\
\end{array}$ & $\begin{array}{l}0 \\
0\end{array}$ & 0.66 & 0.54 & 0.38 & 0.79 & 0.59 & 0.63 \\
\hline
\end{tabular}

Table 8. Values of the parameters $m_{\mathrm{j}}, m_{\mathrm{j}}^{\prime}, \theta_{\mathrm{j}}$ and $\theta_{\mathrm{j}}^{\prime}$ in the $4.2-283 \mathrm{~K}$ temperature range with a comparison between the calculated $M_{\mathrm{S}}$ cal and measured $M_{\mathrm{S}}{ }^{\text {mes }}$ magnetizations.

The thermal variations of the parallel $\left(m_{\mathrm{j}} / /, m^{\prime} \mathrm{j} /\right)$ and perpendicular $\left(m_{\mathrm{j}} \perp, m_{\mathrm{j}}^{\prime} \perp\right)$ components are also reported in Fig. 17. The double umbrella magnetic structure appears to close slowly around the $<111>$ direction in the three magnetic glide planes c' near $160 \mathrm{~K}$ with an abrupt increase between 54 and $68 \mathrm{~K}$. Previous temperature dependences of the calculated non collinear magnetic structure in TbIG (Druzhinina \& Shkarubskii, 1988) and the recent neutron scattering on TbIG single crystal, (Louca et al., 2009) are not consistent with these thermal variations. In another recent study of the magnetic and magneto-optical properties of the $\mathrm{Tb}^{3+}$ ions in TbIG and in the mixed system of terbium-yttrium ferrites garnets $\mathrm{Tb}_{x} \mathrm{Y}_{3-}$ ${ }_{x} \mathrm{IG}(\mathrm{x}<1)$ (Zhang et al., 2009) the differences between the two non collinear magnetic structures which exist at low temperature were not taken account in their calculations. 

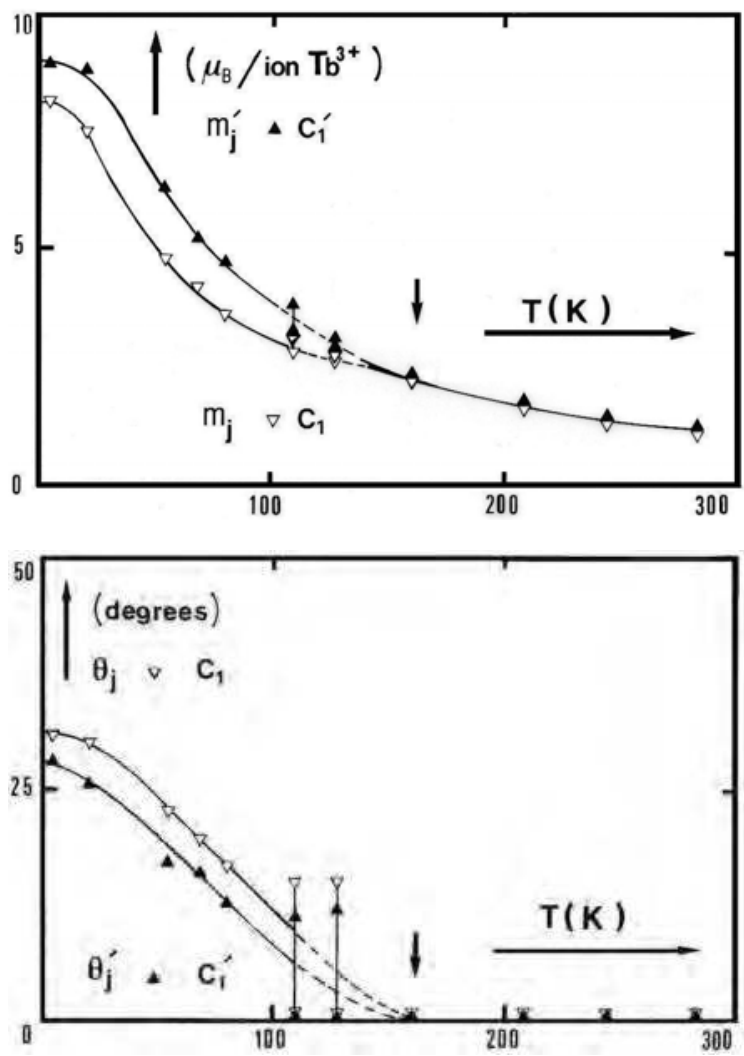

Fig. 16. Thermal variations of the parameters $\left(m_{\mathfrak{j}}, m_{\mathfrak{j}}^{\prime}\right)$ and $\left(\theta_{\mathrm{j}}, \theta_{\mathrm{j}}^{\prime}\right)$

The $<111>$ direction ceases to be the easy axis of magnetization and changes below $140 \mathrm{~K}$ to the $<100>$ direction up to $4.2 \mathrm{~K}$ in $\mathrm{Tb}_{0.37} \mathrm{Y}_{2.63} \mathrm{IG}$ for example with the appearance of the low symmetry phases <uuw $>$ (Lahoubi et al, 2000) in the spontaneous spin reorientation phase transitions.

These results are in good agreement with the previous observed rhombohedral distortion below $190 \mathrm{~K}$ (Rodić \& Guillot, 1990) and $200 \mathrm{~K}$ (Sayetat, 1974, 1986). They are also in good agreement with the anomalous behaviors observed previously below $200 \mathrm{~K}$ on TbIG single crystals without applied magnetic fields, in the acoustic properties (Kvashnina et al., 1984; Smokotin et al., 1985) and in the elastic constant measurements (Alberts et al., 1988) along the [100], [110] and [111] crystallographic directions, precisely in the temperature ranges, $60-140 \mathrm{~K}$ and $50-165 \mathrm{~K}$ respectively.

It seems that the behavior around $160 \mathrm{~K}$ has a relation with the previous predicted momentum angular compensation point $T_{\mathrm{J}}$ (Nelson \& Mayer, 1971) localized at 150 and 190 $\mathrm{K}$ by assuming the free and quenched ion value respectively.

The large magnetodielectric (MD) effects which have been recently revealed on TbIG single crystal at low temperature as well when a very small external magnetic field $\left(H_{\mathrm{ex}}<0.2 \mathrm{~T}\right)$ is 

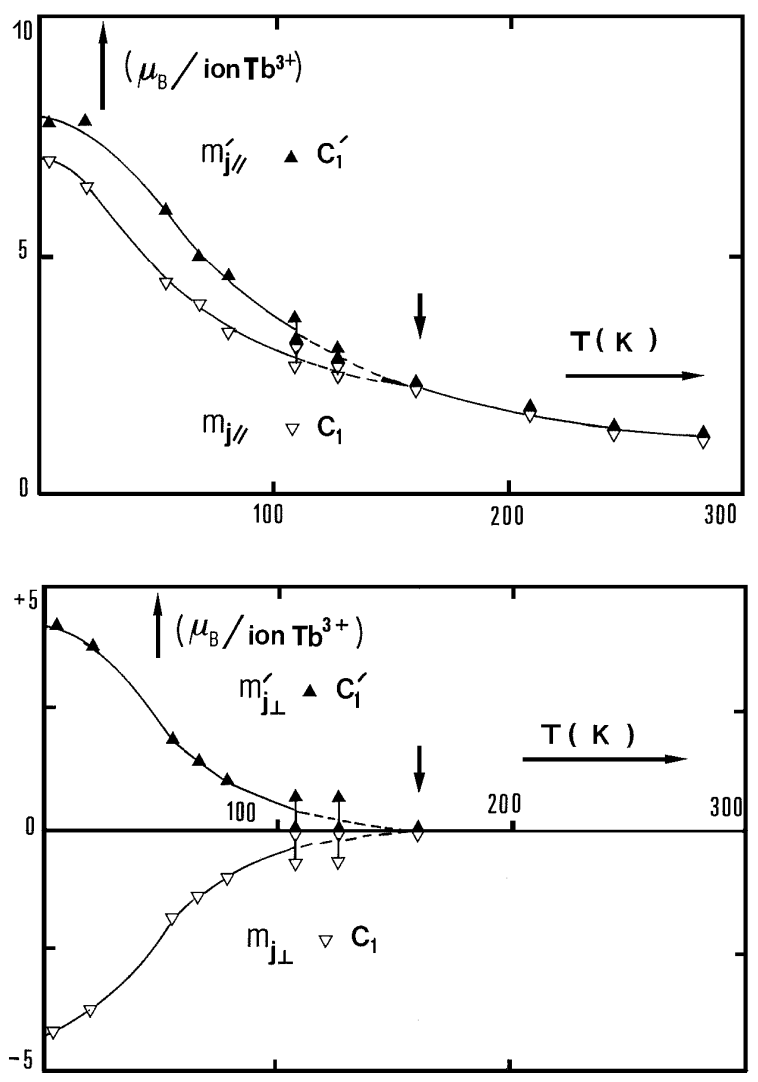

Fig. 17. Thermal variations of the parameters $\left(m_{j} / /, m_{j} \perp\right)$ and $\left(m_{j}^{\prime} / /, m_{j}^{\prime} \perp\right)$

applied (Hur et al., 2005) could be combined with the previous huge spontaneous magnetostriction measurements (Sayetat, 1974, 1986; Guillot et al., 1980) where a peak near $70 \mathrm{~K}$ has been observed in the thermal variations of $\lambda \varepsilon, 2\left(\mathrm{~Tb}^{3+}\right)_{\exp } / \lambda \varepsilon, 2\left(\mathrm{~Tb}^{3+}\right)_{\mathrm{cal}}$, the ratio of the experimental values of the magnetostriction constant to the theoretical values derived from the one ion model. It correspond to the abrupt change in the long-range magnetic order in the $\mathrm{Tb}^{3+}$ sublattice near the previous predicted low-temperature point $T_{\mathrm{B}}=58 \mathrm{~K}$ (Belov, 1996 and refs. herein) which is situated between 54 and $68 \mathrm{~K}$ in this study. More recently, some magnetoelectric (ME) and MD effects in weak and high external magnetic fields ( $H_{\mathrm{ex}}$ up to $2 \mathrm{~T}$ and $H_{\text {ex }}$ up to $10 \mathrm{~T}$ respectively) have been reported (Kang et al., 2010). A possible coupling between the magnetic exchange and the ligand-field excitations which occurs at a specific temperature situated between 60 and $80 \mathrm{~K}$ has been discovered without external magnetic field $\left(H_{\mathrm{ex}}=0\right)$ with two distinct behaviors above and below another characteristic temperature $(\sim 150 \mathrm{~K})$. All results confirm that Landau's theory of second order phase transitions does not apply to TbIG in the $5 \mathrm{~K}-T_{\mathrm{N}}$ temperature range without applied external magnetic field and the magnetic space group is $\mathrm{R} \overline{3} c^{\prime}$ (Bertaut, 1997; Lahoubi et al., 1997). 


\section{Conclusion}

In this chapter, the temperature evolution of the magnetic structure in TbIG is studied by neutron diffraction experiments below $T_{\mathrm{N}}(568 \mathrm{~K})$. The "double umbrella" structure observed at $5 \mathrm{~K}$ appears below a specific temperature $(\sim 160 \mathrm{~K})$ which could be related to the previous predicted $T_{\mathrm{J}}$-point situated in the $150-190 \mathrm{~K}$ temperature range. The rapid variation of the $\mathrm{Tb}^{3+}$ moments is observed between 54 and $68 \mathrm{~K}$ where the predicted value (58 K) of the $T_{\mathrm{B}}$-point is located. The magnetic symmetry doesn't change with the temperature and the magnetic space group is $R \overline{3} c^{\prime}$. The author is convinced that the symmetry considerations of the Representation Analysis of Bertaut presented in this chapter have demonstrated their usefulness in the determination of the thermal variation of the double umbrella magnetic structure in TbIG below $T_{\mathrm{N}}$. It is hoped that these results which are in good agreement with the magnetization measurements will facilitate a better understanding of the possible correlations between the magnetic properties via the double umbrella magnetic structure and the recent ME and MD effects found in this ferrite garnet.

\section{Acknowledgements}

This work is dedicated to the Academician Dr. E F Lewy Bertaut, the father "on group theoretical techniques in magnetic structure analysis", who died in 2003. Some of unpublished results presented here constitute a part of my thesis. I am indebted to Dr. M Guillot (LNCMI, Grenoble) for his experimental contribution as supervisor and for providing the samples. We thank Dr. F Tchéou (UJF, Grenoble) for his helpful discussions during the refinement of the neutron diffraction patterns. Many acknowledgements are also addressed to Dr. B Ouladdiaf (ILL, Grenoble) for his assistance during the recent D1B experiments.

\section{References}

Alberts, H. L.; Palmer, S. B. \& Patterson, C. (1988). J. Phys. C: Solid State Phys., Vol. 21, pp. 271-275

Bacon, G. E. (1972). Acta. Cryst. A, Vol. 28, pp. 357-358

Bacon, G. E. (1975). Neutron Diffraction, (Third Edition), Clarendon Press, Oxford, UK

Belov, K. P. (1996). Phys. Usp., Vol. 39, No. 6, pp. 623-634

Bertaut, E. F. \& Forrat, F. (1956a). C. R. Acad. Sci., Paris, Vol. 242, pp. 382-384

Bertaut, E. F.; Forrat, F.; Herpin, A. \& Mériel, P. (1956b). C. R. Acad. Sci., Paris, Vol. 243, pp. 898-901

Bertaut, E. F. (1963). Spin Configurations of Ionic Structures: Theory and Practice, In: Treatise on Magnetism, Suhl \& Rado, Vol. III, Chap. 4, pp. 149-209, Acad. Press, New York

Bertaut, E. F. (1968). Acta Cryst. A, Vol. 24, No.1, pp. 217-231

Bertaut, E. F.; Sayetat, F. \& Tchéou, F. (1970). Solid State Commun., Vol. 8, No.4, pp. 239-245

Bertaut, E. F. (1971). J. Phys., Colloque C1, Suppl. No. 2-3, t. 32, pp. C1. 462-470

Bertaut, E. F. (1972). Ann. Phys., t. 7, pp. 203-232

Bertaut, E. F. (1981). J. Magn. Magn. Mater.,Vol. 24, pp. 267-278

Bertaut, E. F. (1997). J. Phys. IV France 7, Colloque C1, Suppl. J. Phys III, pp. C1.11-26

Blume, M.; Freeman, A. J. \& Watson, R. E. (1962). J. Chem. Phys., Vol. 37, pp. 1245-1253

Bonnet, M. (1976). Thesis, Doct. of Sciences in Physics, Grenoble University, France 
Bonnet, M.; Delapalme, A.; Fuess, H. \& Becker, P. (1979). J. Phys. Chem. Solids, Vol. 40, (No. 11), pp. 863-876

Chatterji, T. (2006). Editor, Neutron Scattering from Magnetic Materials, Elsevier B.V., pp. 1-559

Convert, P.; Fruchart, D.; Roudaut, E. \& Wolfers, P. (1983). 12 Years of Life with Bananas (Curved One-Dimensional Neutron PSDs), In: Position-Sensitive Detection $\mathcal{E}$ Thermal Neutrons, pp. 302-309, Academic Press Inc., ISBN: 0-12-186180-5, London, UK

Druzhinina, R. F. \& Shkarubskii, V.V. (1988). Sov. Phys. Solid State, Vol. 30, (No. 2), pp. 342343

Ferey, G.; De Pape, R.; Le Blanc, M. \& Pannetier, J. (1986). Rev. Chim. Miner., Vol. 23, pp. 474-484

Flury Jr, R. L. (1980). Symmetry Groups: Theory and Chemical Applications, Prentice-Hall, Inc., Englewood Cliffs, New-Jersey 07632

Fuess, H.; Bassi, G.; Bonnet, M. \& Delapalme, A. (1976). Solid State Commun., Vol. 18, (No. 5) pp. $557-562$

Geller, S. (1978). Crystal and Static Magnetic Properties of Garnets, In: Proc. of the International School of Physics "Enrico Fermi", 1977, Course LXX, Physics of magnetic Garnets, A. Paoletti (Ed.), pp. 1-55, North-Holland Publishing Co, Amsterdam

Geller, S. \& Gilleo, M. A. (1957a). Acta. Cryst., Vol. 10, p. 239

Geller, S. \& Gilleo, M. A. (1957b). J. Phys. Chem. Solids, Vol. 3, (No.1-2), pp. 30-36

Gonano, R.; Hunt, E. \& Meyer, H. (1967). Phys. Rev., Vol. 156, pp. 521-533

Guillot, M. \& du Tremolet de Lacheisserie, E. (1980). Z. Phys. B-Condensed Matter, Vol. 39, pp. 109-114

Guillot, M.; Marchand, A.; Tchéou, F \& Feldmann, P (1982). J. Appl. Phys., Vol. 53, (No.3), pp. 2719-2721

Guillot, M.; Tchéou, F.; Marchand, A. \& Feldmann, P. (1983).J. Magn. Magn. Mater.,Vol. 3134, pp. 631-632

Guillot, M.; Tchéou, F.; Marchand, A. \& Feldmann, P. (1984). Z. Phys. B - Condensed Matter, Vol. 56, pp. 29-39

Guillot, M. (1994). Magnetic Properties of Ferrites, In: Materials Science and Technology: A Comprehensive Treatment, Cahn, Haasen \& Kramer, (editors), Vol. 3B, Electronic and Magnetic Properties of Metals and Ceramics, Part II, VCH Publishers Inc., Chapter 8, K. H. J. Buschow (Ed.), pp. 7-92, VCH Verlagsgesellschaft mbH, VCH Publishers Inc. Weinheim, New York, USA

Hahn, Th. (1983). (Ed.) Space Group Symmetry, Vol. A, In: International Tables for Crystallography, Published by the IUCr, Dordrecht Reidel Boston, London, kluwer academic publisher's edition

Herpin, A. (1968). Théorie du Magnétisme, Puf, Paris, France

Herpin, A.; Koehler, W. \& Meriel, P. (1960). C. R. Acad. Sci., Vol. 251, p. 1359

Hock, R.; Fuess, H.; Vogt, T \& Bonnet, M. (1990). J. of Solid State Chem.,Vol. 84, (No. 1) pp.3951

Hock, R.; Fuess, H.; Vogt, T \& Bonnet, M. (1991). Z. Phys. B-Cond. Matter, Vol. 82, pp. 283-294

Hong, Y. J.; Kum, J.S.; Shim, I. B. \& Kim, C. S. (2004). I.E.E.E. Trans. on Magn., Vol. 40, (No. 4), pp. 2808-2810

Hur, N.; Park, S.; Guha, S.; Borissov, A.; Kiryukhin, V. \& Cheong, S.-W. (2005). Appl. Phys. Lett., Vol. 87, (No.4), 042901(3 pages)

Kahan, T. (1972). Théorie des Groupes en Physique Classique et Quantique, tome 3, Dunod, Paris 
Kang, T. D.; Standard, E.; Ahn, K. H.; Sirenko, A. A.; Carr, G. L.; Park, S.; Choi, Y. J.; Ramazanoglu, M.; Kiryukhin, V. \& Cheong, S.-W. (2010). Phys. Rev. B, Vol. 82, (No.1), 014414 (7 pages)

Kazei, Z. A.; Kolmakova, N.P.; Novak, P. \& Sokolov, V. I. (1991). Magnetic Properties of Non-Metallic Inorganic Compounds Based on Transition Elements, In: LandoltBörnstein Group III, H. P. J. Wijn (Ed.), Vol. 27, ISBN 3-540-53963-8, Springer Verlag edition, Berlin Heidelberg

Kvashnini, O. P.; Kapitonov, A. M.; Smokotin, É. M. \& Titova, A. G. (1984). Sov. Phys. Solid State, Vol. 26, (No.8), pp. 1458-1459

Lahoubi, M.; Guillot, M.; Marchand, A.; Tchéou, F. \& Roudaut, E. (1984). I.E.E.E. Trans. on Magn., Vol. MAG-20, (No. 5), pp. 1518-1520

Lahoubi, M.; Guillot, M.; Marchand, A.; Tchéou, F. \& Le Gall, H. (1985). High MagneticField Magnetization in Terbium Iron Garnet (TbIG), In: Advances in Ceramics, Proceedings of the Fourth Inter. Conf. on Ferrites (ICF4), Vol. 15, Part I, Wang F. F. Y. (Ed.), pp. 275-282, ISSN 0730-9546, San Francisco, USA, Oct.31-Nov.2, 1984

Lahoubi, M. (1986). Thesis, Doct. of Sciences in Physics, Grenoble University, France, pp.1-245

Lahoubi, M.; Fillion, G. \& Tchéou, F. (1997). J. Phys. IV France 7, Colloque C1, Suppl. J. Phys III, pp. C1. 291-292

Lahoubi, M.; Kihal, A. \& Fillion, G. (2000). Physica B, Vol. 284-288, pp. 1503-1504

Lahoubi, M.; Younsi, W.; Soltani, M.-L.; Voiron, J. \& Schmitt, D. (2009). J. Phys.: Conf. Ser., Vol. 150, 042108(4 pages)

Lahoubi, M.; Younsi, W.; Soltani, M.-L. \& Ouladdiaf, B. (2010). J. Phys.: Conf. Ser., Vol. 200, 082018(4 pages)

Lahoubi, M. (2012). Symmetry Analysis of the Magnetic Structures in TbIG and Tb:YIG at Low Temperature, In: J. Phys.: Conf. Ser., Vol. 340, 012068(10 pages) Proceedings of the $5^{\text {th }}$ European Conf. on Neutron Scattering, Prague, Czech Republic, July 17-22, 2011

Levitin, R. Z.; Markosyan, A. S. \& Orlov, V. N. (1983). Sov. Phys. Solid State, Vol. 25, (No. 6), pp. 1074-1075

Louca, D.; Kamazawa, K \& Proffen, T. (2009). Phys. Rev. B, Vol. 80, 214406(6 pages)

Nathans, R.; Shull, C. G.; Shirane, G. \& Andresen, A. (1959). J. Phys. Chem. Solids, Vol. 10, (No. 2-3), pp. 138-146

Néel, L. (1948). Ann. Phys. Paris, Vol. 3, pp. 137-198

Nelson T. J. \& Mayer D.C. (1971). I.E.E.E. Trans. on Magn., Vol. 7, (No. 3), pp. 616-617

Nekvasil, V. \& Veltrusky, I. (1990). J. Magn. Magn. Mater., Vol. 86, pp. 315-325

Pauthenet, R. (1958a). Ann. Phys., Paris, Vol. 3, pp. 424

Pauthenet, R. (1958b). Thesis Doct. of Sciences in Physics, Grenoble University, France, pp.1-39

Pearson, R. F. (1965). Proc. Phys. Soc.,Vol. 86, pp. 1055-1066

Pickart, S. J.; Halperin, H. A. \& Clark, A. E. (1970). J. Appl. Phys., Vol. 41, pp.1192-1193

Rodić, D. \& Guillot, M. (1990). J. Magn. Magn. Mater., Vol. 86, pp. 7-12

Roudaut, E. (1983). Evolution of Position-Sensitive Detectors for Neutron Diffraction Experiments From 1966 to 1982 in the Nuclear Centre of Grenoble, In: PositionSensitive Detection E Thermal Neutrons, pp. 294-301, Academic Press Inc., ISBN: 0-12186180-5, London, UK

Sayetat, F. (1974). Thesis, Doct. of Sciences in Physics, Grenoble University, France

Sayetat, F. (1986). J. Magn. Magn. Mater., Vol. 58, pp. 334-346

Shull, C. G. \& Smart, J. S. (1949). Phys. Rev. Vol. 76, pp. 1256-1257 
Smokotin, É. M., Kvashnini O. P. \& Kapitonov, A. M. (1985). Phys. Status Solidi (a) Vol. 87, K pp. 53-56

Tchéou, F.; Bertaut, E. F.; Delapalme, A.; Sayetat, F. \& Fuess, H. (1970a). Colloque International C.N.R.S. "Les Eléments des Terre Rares" 180, Vol. II, pp. 313-332

Tchéou, F.; Bertaut, E. F. \& Fuess, H. (1970b). Solid State Commun., Vol. 8, pp. 1751-1758

Tchéou, F.; Fuess, H. \& Bertaut, E. F. (1970c). Solid State Commun., Vol. 8, pp. 1745-1749

Watson, R. E. \& Fremann, A. J. (1961). Acta. Cryst., Vol. 14 pp. 27-37

Wills, A. S. (2007). Zeitschrift für Kristallographie, Suppl., Vol. 26, pp. 53-58

Wolf, W. P.; Ball, M.; Hutchings, M. T.; Leask, M. J. M. \& Wyatt, A. F. G. (1962). J. Phys. Soc. Japan, Vol. 17, Suppl., B-I, pp. 443-448

Wolf, W. P. (1964). Local Anisotropy in Rare earth Garnets, In: Proceedings of the International Conference on Magnetism (ICM) Nottingham, pp. 555-560

Zhang, G.-y.; Wei, M.; Xia, W.-s. \& Yang. G. (2009). J. Magn. Magn. Mater.,Vol. 321, pp. 30773079

Zvezdin, A. K. (1995). Field Induced Phase Transitions in Ferrimagnets, In: Handbook of Magnetic Materials, K. H. J. Buschow (Ed.), 4, Vol. 9, pp. 405-543, Elsevier Science, Amsterdam 


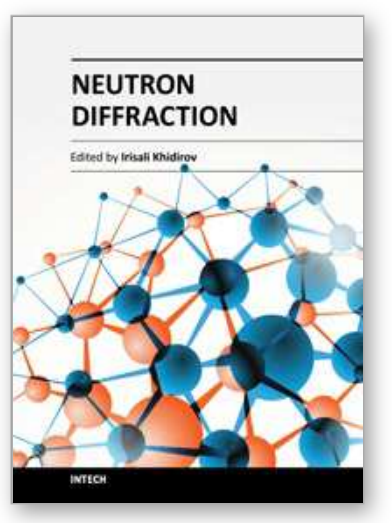

\author{
Neutron Diffraction \\ Edited by Prof. Irisali Khidirov
}

ISBN 978-953-51-0307-3

Hard cover, 286 pages

Publisher InTech

Published online 14, March, 2012

Published in print edition March, 2012

Now neutron diffraction is widely applied for the research of crystal, magnetic structure and internal stress of crystalline materials of various classes, including nanocrystalls. In the present book, we make practically short excursion to modern state of neutron diffraction researches of crystal materials of various classes. The book contains a helpful information on a modern state of neutron diffraction researches of crystals for the broad specialists interested in studying crystals and purposeful regulation of their service characteristics, since the crystal structure, basically, defines their physical and mechanical properties. Some chapters of the book have methodical character that can be useful to scientists, interested in possibilities of neutron diffraction. We hope, that results of last years presented in the book, can be a push to new ideas in studying of crystalline, magnetic structure and a macrostructure of usual crystal materials and nanocrystals. In turn, it can promote working out of new materials with new improved service characteristics and to origin of innovative ideas.

\title{
How to reference
}

In order to correctly reference this scholarly work, feel free to copy and paste the following:

Mahieddine Lahoubi (2012). Temperature Evolution of the Double Umbrella Magnetic Structure in Terbium Iron Garnet, Neutron Diffraction, Prof. Irisali Khidirov (Ed.), ISBN: 978-953-51-0307-3, InTech, Available from: http://www.intechopen.com/books/neutron-diffraction/temperature-evolution-of-the-double-umbrella-magneticstructure-in-terbium-iron-garnet-

\section{INTECH}

open science | open minds

\author{
InTech Europe \\ University Campus STeP Ri \\ Slavka Krautzeka 83/A \\ 51000 Rijeka, Croatia \\ Phone: +385 (51) 770447 \\ Fax: +385 (51) 686166 \\ www.intechopen.com
}

\author{
InTech China \\ Unit 405, Office Block, Hotel Equatorial Shanghai \\ No.65, Yan An Road (West), Shanghai, 200040, China \\ 中国上海市延安西路65号上海国际贵都大饭店办公楼 405 单元 \\ Phone: +86-21-62489820 \\ Fax: $+86-21-62489821$
}


(C) 2012 The Author(s). Licensee IntechOpen. This is an open access article distributed under the terms of the Creative Commons Attribution 3.0 License, which permits unrestricted use, distribution, and reproduction in any medium, provided the original work is properly cited. 